\title{
Can Behavioral Tools Improve Online Student Outcomes? Experimental Evidence from a Massive Open Online Course
}

\author{
Richard W. Patterson ${ }^{1}$
}

April 9, 2015

\begin{abstract}
Online education is an increasingly popular alternative to traditional classroombased courses. However, completion rates in online courses are often very low. One explanation for poor performance in online courses is that aspects of the online environment lead students to procrastinate, forget about, or be distracted from coursework. To address student time-management issues, I leverage insights from behavioral economics to design three software tools including (1) a commitment device that allows students to pre-commit to time limits on distracting Internet activities, (2) a reminder tool that is triggered by time spent on distracting websites, and (3) a focusing tool that allows students to block distracting sites when they go to the course website. I test the impact of these tools in a large-scale randomized experiment $(n=657)$ conducted in a massive open online course (MOOC) hosted by Stanford University. Relative to students in the control group, students in the commitment device treatment spend $24 \%$ more time working on the course, receive course grades that are 0.29 standard deviations higher, and are $40 \%$ more likely to complete the course. In contrast, outcomes for students in the reminder and focusing treatments are not statistically distinguishable from the control. These results suggest that tools designed to address procrastination can have a significant impact on online student performance.
\end{abstract}

\footnotetext{
${ }^{1}$ Department of Policy Analysis and Management, Cornell University (email: rwp83@cornell.edu). I thank the National Academy of Education, Spencer Foundation, the Russell Sage Foundation, and the Cornell Institute for the Social Sciences for their financial support of this research. I thank Daniel Greene for collaborating on the experimental design and implementation at Stanford University. I also thank Daniel Benjamin, Damon Clark, Ronald Ehrenberg, Tatiana Homonoff, Jordan Matsudaira, Ted O'Donoghue and Cornell seminar participants for their feedback and insights. All errors are my own.
} 


\section{Introduction}

Richard W. Patterson

People frequently fail to follow through on the plans they make: they fail to meet deadlines at work, finish assignments for school, go to the gym, and deposit money in their savings accounts. In higher education, only $59 \%$ of students complete the degree programs they begin, ${ }^{1}$ and completion rates are often much lower in online programs and courses. For example, the graduation rate at the University of Phoenix, the largest provider of online degrees in the United States, is only $19 \% .^{2}$ and in massive open online courses (MOOCs), which allow thousands of students to simultaneously access course material, completion rates are often less than 10\% (Perna et al., 2013).

The standard neoclassical economic model assumes that people make plans that maximize their intertemporal utility and that they only will deviate from their plans when doing so improves their overall well-being. Evidence from psychology and behavioral economics, however, suggests that people may systematically deviate from their plans in ways that significantly decrease their well-being. In particular, procrastination (Laibson, 1997), forgetting (Mullainathan, 2002), and limited willpower (Baumeister et al., 1998) may lead to detrimental deviations from long-run plans. In environments such as online education, where behavioral factors are likely to keep people from following their plans, interventions such as commitment devices and reminders may significantly increase plan completion and improve well-being. ${ }^{3}$

In this study, I design time-management software tools for online students and experi-

\footnotetext{
${ }^{1}$ Source: http://nces.ed.gov/programs/digest/d13/tables/dt13_326.10.asp, 10/29/2014.

${ }^{2}$ Source: http://nces.ed.gov/ipeds/datacenter/institutionprofile.aspx?unitId=aeb2adadacae, October 12, 2014.

${ }^{3}$ While little work has been done to investigate the impact of commitment devices and reminders in education, there is evidence of the effectiveness of commitment devices and reminders in other settings. Commitment devices have been shown to significantly improve effort at work, savings behavior, and health behaviors (Ashraf et al., 2006; Bryan et al., 2010; Kaur et al., 2011). Additionally, recent studies have found significant positive impacts of reminders on savings behavior (Karlan et al., 2010) and health outcomes (Calzolari and Nardotto, 2012; Krishna et al., 2009; Austin et al., 1994)
} 
Richard W. Patterson mentally test the impact of these tools in a statistics MOOC hosted by Stanford University. These tools include a commitment device, which enables students to pre-commit to daily time limits on distracting Internet activities; a reminder tool, which generates an on-screen reminder that is triggered by distracted web browsing; and a focusing tool, which allows students to block distracting websites for up to an hour when they go to the course website. If students struggle with time-management issues, the software treatments may improve student performance and well-being.

My results indicate that the commitment device significantly improves course outcomes relative to the control, reminder, and focusing treatments. I find that the commitment device increases course completion by $40 \%$ (11 percentage points), improves overall course performance by 0.29 standard deviations, and increases the amount of time students spend on the course website by $24 \%$ ( 5.5 hours) relative to the control. Estimates for the impact of the focusing treatment on course outcomes are also positive but smaller in magnitude than the commitment device and are not statistically significant. The reminder treatment, however, has no measurable impact on course outcomes. I also find that the differences between the commitment and control are most pronounced in the first weeks of the course and are largest among students who were predicted to do well in the course, given their observable characteristics. In all, this study suggests that procrastination plays a significant role in poor performance among online students, and that commitment devices can have a significant impact on student performance.

This study contributes to the existing literature in several ways. First, this is one of the first studies to test whether tools from behavioral economics can improve completion rates in online education. Second, this study adds insight into the mechanisms driving poor outcomes for online students. Third, by simultaneously testing multiple behavioral tools, this study informs the relative efficacy of interventions intended to address different sources of time-management issues. 


\section{Background and Motivation}

Richard W. Patterson

\subsection{Online Education}

Online courses are quickly becoming a mainstay in higher education. Between 2002 and 2012, the percentage of online universities offering online courses grew from $72 \%$ to $87 \%$, the percentage of students taking online courses grew from 9\% to 34\%, (Allen and Seaman, 2013) and the percentage of undergraduate students enrolled in distance or online-only degree programs grew from 2\% to $11 \%$ (Ginder and Stearns, 2014). In addition to a growing number schools offering online courses as part of accredited degree programs, a number of selective universities, such as Harvard, Stanford, and Cornell now offer Internet-based massive open online courses (MOOCs) to a global population. MOOCs are designed to accommodate thousands of students and have the potential dramatically broaden access to high-quality instruction. MOOCs typically have open enrollment, are free to join, and have no penalty for dropping out. To date, nearly 8 million students have enrolled in MOOCs to learn material from a broad range of subjects; including science, business, mathematics, information technology, arts, and humanities (Waldrop, 2014).

While the potential benefits of online eduction are large, completion rates are often very low. For example, Xu and Jaggars (2011) find that observationally equivalent community college students are 10-15 percentage points less likely to complete online courses than traditional courses. At the University of Phoenix, the largest provider of online degrees in the United States, the graduation rate for full-time online students is only $19 \%{ }^{4}$ In MOOCs, completion rates are often even lower. Perna et al. (2013) examined the completion rates for approximately 1 million students from 16 University of Pennsylvania MOOCs and found that only $6 \%$ of students completed the course in which they enrolled. ${ }^{5}$

\footnotetext{
${ }^{4}$ This graduate rate accounts for all graduations within 6 years. Source: http://nces.ed.gov/ipeds/datacenter/institutionprofile.aspx?unitId=aeb2adadacae, October 12, 2014.

${ }^{5}$ Perna et al. (2013) define completion by scoring at least an $80 \%$ in the course. The authors also find
} 
Richard W. Patterson

Although the low completion rates in MOOCs and other online courses are striking, they do not necessarily indicate that students are behaving irrationally. However, there is evidence that suggests that many students drop out of courses they would have liked to finish and that behavioral factors may contribute to high dropout rates. For example, Wilkowski et al. (2014) examine completion behavior in a MOOC hosted by Google, and find that less than $25 \%$ of students who report a goal of earning a certificate of completion ultimately finish the course. Additionally, a number of studies find that students report self-regulation and time-management problems as primary reasons for failure in online courses (e.g. Doherty, 2006; Winters et al., 2008). While issues of self-regulation and time-management are likely to impact all students, aspects of the online learning environment may make students particularly susceptible to issues with time-management. Specifically, characteristics of the online course environment, such as anonymity (e.g. Kast et al., 2012) and unstructured scheduling (e.g. Ariely and Wertenbroch, 2002), make students prone to behaviors that could limit their ability to achieve their course goals. Given the disparity between desired and realized outcomes for online students, identifying and addressing behavioral barriers to online academic success could provide significant benefits to students.

\subsection{Time-inconsistent Preferences and Commitment Devices}

One reason online students may fail to achieve their long-run course goals is that they behave impatiently and procrastinate their coursework. Economic models of intertemporal choice such as present-biased preferences (Laibson, 1997; O'Donoghue and Rabin, 1999) and dual-self models of self-control (Fudenberg and Levine, 2006) predict this type of impatient, time-inconsistent behavior. ${ }^{6}$ The influence of time-inconsistent behavior may be particularly

that only $9 \%$ of students accessed the last lecture in the course in which they enrolled.

${ }^{6}$ Time-inconsistent preferences describe a situation where the value of trade-offs between two different moments changes over time (Laibson, 1997). Perhaps the most common form of time-inconsistent preferences is procrastination - where individuals behave more impatiently in the moment than they would have liked to from a prior perspective. 
Richard W. Patterson important in education settings where the benefits of increased effort are often realized far in the future. For example, Levitt et al. (2012) find evidence of time-inconsistency among high-school students who perform significantly better on standardized tests when they are offered a financial incentive that is delivered immediately following the test, but perform no better than a control group when the financial incentive is delayed by just a month.

While impatience may lead to detrimental outcomes for online students, both theory and evidence from the field suggest that commitment devices can help people who are aware of their time-inconsistent behavior to bring their short-run behavior in line with their long-run interests. ${ }^{7}$ Commitment devices can increase the likelihood that an individual will behave patiently by making future procrastination more difficult or costly (Bryan et al., 2010). Commitment devices have been shown to significantly increase desired long-run behaviors including effort at work (Kaur et al., 2011), savings behavior (Ashraf et al., 2006; Thaler and Benartzi, 2004), and smoking cessation (Giné et al., 2010). While there is limited evidence of the impact of formal commitment devices in education, Ariely and Wertenbroch (2002) find that students hired to proofread multiple papers over a three week span performed significantly better when given the option to set binding intermediate deadlines. ${ }^{8}$ If presentbiased preferences are a significant detriment to performance in online education, providing online students with formal commitment devices may help them achieve their course goals.

\subsection{Limited Memory and Reminders}

In addition to behaving impatiently, online students may forget about their coursework. If online students experience failures of prospective memory, or forget about their prior

\footnotetext{
${ }^{7}$ If people are naïve about their time-inconsistent preferences and mistakenly believe that they will behave patiently in the future, then they are unlikely to seek out and use commitment devices.

${ }^{8}$ Students who were given equally spaced deadlines for each paper, however, outperformed both those given one deadline or the option to set multiple deadlines. This evidence is consistent with the students exhibiting some level of naïvete about their time-inconsistent preferences.
} 
Richard W. Patterson intentions or plans, they may not achieve their course goals. ${ }^{9}$ Economic models of limited prospective memory and inattention (e.g. Mullainathan, 2002; Ericson, 2014; Karlan et al., 2010; Taubinsky, 2014) predict that people will forget to follow through on their plans in ways that significantly reduce their well-being.

A simple way to address limited memory is to provide individuals access to reminder technologies. ${ }^{10}$ Reminders have been shown to increase college matriculation (Castleman and Page, 2014), repayment of loans (Cadena and Schoar, 2011), savings accounts deposits (Karlan et al., 2010), medication adherence (Zogg et al., 2012), and exercise (Calzolari and Nardotto, 2012). Given that online students must have access to a computer in order to complete their work, it is likely that they already have access to computerized reminder technologies (e.g. email, calendar, reminder software) which may limit the impact of additional reminders. However, if available reminder technologies are difficult to use or if students are over-confident in their ability to remember their plans, providing reminders may be an effective way to help students achieve their course goals. ${ }^{11}$

\subsection{Limited Willpower}

Another factor that may limit students' ability to complete their goals is limited willpower. Theories in economics (e.g. Ozdenoren et al., 2012; Fudenberg and Levine, 2012) and psychology (e.g. Baumeister and Vohs, 2003) model willpower as a depletable resource and suggest that resisting temptation reduces one's subsequent ability to exercise willpower. For instance, Baumeister et al. (1998) find that subjects who were required to resist the temp-

\footnotetext{
${ }^{9}$ See McDaniel and Einstein (2007) for a review of prospective memory.

${ }^{10}$ While most models of limited memory (e.g. (Karlan et al., 2010; Taubinsky, 2014) predict that reminders will increase plan completion, Ericson (2014) suggests that reminders may reduce plan completion among present-biased individuals under certain circumstances.

${ }^{11}$ There is evidence that people are overconfident in their ability to remember their plans. For example, Ericson (2011) finds that MBA students significantly overestimate their ability to remember to claim a payment in six months. Students' decisions suggest an expectation of claiming payments $76 \%$ of the time, while only $53 \%$ of students actually claim the payment.
} 
Richard W. Patterson tation to eat chocolate in the first stage of an experiment exerted significantly less effort on a puzzle task in the second stage of the study. If students have limited willpower, exposure to factors that tax willpower may leave students too fatigued to complete the course tasks they start. In the context of this study, providing a mechanism to eliminate the temptation of entertaining or distracting websites may increase the willpower students have available to devote to the course.

\section{Experimental Design and Population}

\subsection{Experimental Context and Population}

Participants for this study were recruited from enrollees in a nine-week Stanford statistics massive open online course (MOOC) which was held in 2014. This completely online course was administered by Stanford University on the Stanford OpenEdX platform. ${ }^{12}$ Although the course was administered by Stanford, course enrollment was free, open to anyone worldwide, and provided no formal credit at Stanford University. Students, however, could receive a certificate of completion or certificate with distinction by scoring at least $60 \%$ or $90 \%$ in the course, respectively. Scores for the course were composed of a multiple-choice final exam (45\%), nine weekly homework assignments (45\%), and participation in 53 short quizzes $(10 \%) .{ }^{13}$ The course content was primarily delivered by lecture videos and covered a number of topics in statistics including basic statistical measures, probability distributions, statistical inference, statistical tests, and regression analysis. ${ }^{14}$ Stanford tracked the time students

\footnotetext{
${ }^{12}$ OpenEdX is an open source version of the MOOC platform developed by EdX. While the platform is open source and freely available to all, Stanford retains control of all content, data, and licensing associated with the course.

${ }^{13}$ Students were allowed to take quizzes as many times as they wanted but were only allowed to submit each homework assignment and final exam once. Students were required to submit homework assignments by weekly deadlines in order to receive credit. The lowest grade among the nine homework assignments was dropped. All quiz, homework, and test questions were either multiple-choice or numerical entry and were computer graded.

${ }^{14}$ Supplemental readings and transcripts of lecture videos were also available to students.
} 
spent working on the course and these data were added to the course grade and assignment submission data to construct the academic outcomes that I analyze in this study.

My primary sample consists of the 657 students who participated in the MOOC, completed a pre-study survey, and installed software prior to the first course assignment deadline (a participation rate of $18 \%$ ). ${ }^{15}$ This analysis excludes 120 students who completed the pre-study survey and installed software prior to the first assignment deadline, but never visited the course website. Assignment to treatment condition was uncorrelated with whether students ever visited the course website $(\mathrm{F}=0.5, \mathrm{p}=0.68)$. Students were incentivized to participate with $\$ 12$ in Amazon.com gift cards - $\$ 5$ for completing the enrollment survey and installing time management software and $\$ 7$ for using software and completing a post-study survey. ${ }^{16}$ Participants in this study were randomly assigned to one of four treatment groups: (1) control, (2) commitment device, (3) reminder, and (4) focused study.

Appendix Table A.1.1 reports descriptive statistics for participating students. ${ }^{17}$ Randomization appears to successfully generate balance across treatment groups, with only $2 / 44$ variables differing by treatment at the $5 \%$ level. ${ }^{18}$ Panel A of Appendix Table A.1.1 shows that participating students were highly educated ( $85 \%$ of students have completed college) and geographically dispersed, with only $28 \%$ of students taking the course from the United States. International students predominately took the class from Europe (24\%), Asia (20\%),

\footnotetext{
${ }^{15}$ The $18 \%$ participation rate is calculated among the 3,630 students who enrolled in the course prior to the start date and visited the course at some point during the semester, and excludes individuals who never visit the course website. 240 additional students enrolled in the study after the first week. A majority of these 240 students came from 2,612 students who enrolled in the course after the start date and were recruited to join the study at the beginning of the second week. I focus my analysis on the 657 students who are treated in each week during the course and for whom I am able to analyze a balanced panel of weekly data, but also provide results that include students who enroll during the second week of the course $(\mathbf{n}=897)$ in the appendix.

${ }^{16}$ All study procedures were approved by both Cornell and Stanford University Institutional Review Boards (IRBs) and all students provided informed consent in order to participate.

${ }^{17}$ Statistics reported in Appendix Table A.1.1 were collected in the pre-study survey.

${ }^{18}$ These variables are: whether a student took the course from Africa, and whether the student took the course for work, school, or research. The full list of control variables for the study are listed in Appendix Table A.1.1.
} 
Richard W. Patterson and Africa (13\%). Additionally, Panel B of Appendix Table A.1.2 reveals that students in this study had ambitious course goals, with a majority stating their goal was to finish the course on-time for a certificate of completion (67\%) or to finish all coursework at their own pace $(21 \%)$. The most commonly reported reasons for taking the course were general interest in the topic (94\%), personal growth (93\%), and relevance to work, school, or research (92\%). Panel C of Appendix Table A.1.1 reports variables related to self-control and indicates that, on average, students wanted to decrease the time they spent on distracting websites each day by one hour. Although randomization ensures that estimates of treatment effects are internally valid, selection into study participation may influence the generalizability of the estimates. Appendix Table A.1.2 compares the age, gender, and education level of study participants to other students in the course and indicates that study participants are $11 \%$ more likely to be female and $68 \%$ more likely to hold a Ph.D. or M.D., but are otherwise similar to other students taking the course.

\subsection{Research Design}

Participants in this study were randomly assigned to one of four treatment groups: (1) Control, (2) Commitment Device, (3) Reminder, or (4) Focused Study. Students were assigned to treatment conditions at the individual level by a random number generator embedded in the pre-survey software. To ensure that participants did not differentially select themselves into the study based on the treatment conditions, all students installed the same basic version of the software and were not informed of their software functionality until after they had successfully installed the software and completed the enrollment survey. ${ }^{19}$ The particular functions of the treatment software were not turned on until the course started, or the day

\footnotetext{
${ }^{19}$ I worked with RescueTime, a company that makes time-tracking software, to develop the software tools used in this study. RescueTime implemented the design for each tool and provided software support throughout the study.
} 
following installation if students installed the software after the course began. ${ }^{20}$ The software was designed for all Windows, Linux, and OSX operating systems, and had limited functionality on $\mathrm{iOS}$ and Chrome mobile operating systems. When running, this software tracked and categorized time spent in the active application or browser window. ${ }^{21}$ Each activity was categorized into groups such as email, shopping, news, entertainment, social networking, writing, and education and activity received a productivity score of unproductive, neutral, or productive. ${ }^{22}$ This information collected by the software was used to execute each of the treatment conditions described below. The predicted impact of each treatment is modeled in Appendix B.

\subsubsection{Control}

Students assigned to the control treatment installed the most basic version of the timemanagement software in the study. The control software, like the software in all other treatments, tracked and categorized the student's computer activity. All study participants, including those assigned to the control group, were able to view summary time-use reports of their computer use by connecting to the time-management website (for an example of the time-use report, see Appendix Figure A.1.1). Students in the control group received no other software tools. Students in the control group were given access to these reports in order to justify the request to install time-tracking software, provide a comparable study experience

\footnotetext{
${ }^{20}$ Students who did not complete the enrollment survey or were unable to install software at the time of the survey had software functionality turned on the day after installation, but did not receive messaging explaining their treatment condition.

${ }^{21}$ The software was programmed to automatically run when the participant's computer was turned on. The software could not be closed from any menu option and could only be turned off by manually quitting the application from the computer's task manager/activity monitor function. Activities were tracked logged at the application and web domain level, and keystrokes or actions taken within an application or pages within a web domain were not recorded. If multiple applications or browser tabs were open, the activity was attributed to the application or webpage with the most recent action. When a person stopped interacting with an application or website the software stopped tracking activity even when the application or website remained open.

${ }^{22}$ These categorizations and productivity scores were defined by RescueTime defaults. These defaults were set by an algorithm that combined website query information with aggregated user scores.
} 
Richard W. Patterson to those in the other treatment groups, and to reduce the probability of experimenter demand effects influencing the results (e.g. Zizzo, 2010). ${ }^{23}$ Table 1.1 reports student interaction with the treatment software and shows that over the course of the study, students in the control group accessed summary reports slightly more often (19 times) than those assigned to other treatments (16 times), which is significant at the $10 \%$ level. While it seems unlikely that this difference in accessing reports lead to significant differences in course outcomes, estimates of the impacts of other treatments can be considered lower bounds.

\footnotetext{
${ }^{23}$ Experimenter demand effects refer to experimental subjects changing behavior in order to conform with what an experimenter's apparent expectations.
} 
Richard W. Patterson

Table 1: Treatment Summary Statistics

\begin{tabular}{|c|c|c|c|c|c|}
\hline & Control & Commitment & Reminder & Focus & Total \\
\hline \multicolumn{6}{|l|}{ Software Summary } \\
\hline Days logged on software & $\begin{array}{c}38.32 \\
(24.08)\end{array}$ & $\begin{array}{c}33.75 \\
(24.84)\end{array}$ & $\begin{array}{c}36.75 \\
(24.01)\end{array}$ & $\begin{array}{c}37.45 \\
(25.13)\end{array}$ & $\begin{array}{c}36.60 \\
(24.52)\end{array}$ \\
\hline Avg hours productive & $\begin{array}{c}1.74 \\
(1.49)\end{array}$ & $\begin{array}{c}1.71 \\
(1.42)\end{array}$ & $\begin{array}{c}1.62 \\
(1.34)\end{array}$ & $\begin{array}{c}1.88 \\
(1.47)\end{array}$ & $\begin{array}{c}1.74 \\
(1.43)\end{array}$ \\
\hline Avg hours unproductive & $\begin{array}{c}0.94 \\
(0.97)\end{array}$ & $\begin{array}{c}0.90 \\
(0.93)\end{array}$ & $\begin{array}{l}1.00 \\
(1.33)\end{array}$ & $\begin{array}{c}0.90 \\
(1.03)\end{array}$ & $\begin{array}{c}0.93 \\
(1.08)\end{array}$ \\
\hline Avg hours on course & $\begin{array}{c}0.16 \\
(0.24)\end{array}$ & $\begin{array}{c}0.19 \\
(0.24)\end{array}$ & $\begin{array}{c}0.15 \\
(0.20)\end{array}$ & $\begin{array}{c}0.15 \\
(0.21)\end{array}$ & $\begin{array}{c}0.16 \\
(0.22)\end{array}$ \\
\hline Times visited RescueTime & $\begin{array}{c}18.59 \\
(17.25)\end{array}$ & $\begin{array}{c}15.53 \\
(15.42)\end{array}$ & $\begin{array}{c}17.07 \\
(16.99)\end{array}$ & $\begin{array}{c}15.35 \\
(15.68)\end{array}$ & $\begin{array}{c}16.67 \\
(16.39)\end{array}$ \\
\hline \multicolumn{6}{|l|}{ Commitment Device } \\
\hline Commitment emails sent & - & $\begin{array}{l}67.18 \\
(8.32)\end{array}$ & - & - & - \\
\hline Commitment (hours) & - & $\begin{array}{c}2.69 \\
(2.71)\end{array}$ & - & $\begin{array}{l}- \\
- \\
-\end{array}$ & - \\
\hline Times commitment exceeded & $\begin{array}{l}- \\
- \\
-\end{array}$ & $\begin{array}{c}4.06 \\
(8.25)\end{array}$ & $\begin{array}{l}- \\
- \\
-\end{array}$ & $\begin{array}{l}- \\
- \\
-\end{array}$ & - \\
\hline Times commitment changed & - & $\begin{array}{c}0.92 \\
(1.79)\end{array}$ & - & - & - \\
\hline Avg change (hours) & $\begin{array}{l}- \\
- \\
-\end{array}$ & $\begin{array}{c}2.61 \\
(2.86)\end{array}$ & $\begin{array}{l}- \\
- \\
-\end{array}$ & $\begin{array}{l}- \\
- \\
-\end{array}$ & $\begin{array}{l}- \\
- \\
-\end{array}$ \\
\hline Reminders & & & & & \\
\hline Reminders sent & $\begin{array}{l}- \\
- \\
-\end{array}$ & $\begin{array}{l}- \\
- \\
-\end{array}$ & $\begin{array}{c}48.19 \\
(77.64)\end{array}$ & $\begin{array}{l}- \\
- \\
-\end{array}$ & $\begin{array}{l}- \\
- \\
-\end{array}$ \\
\hline Focus Study & & & & & \\
\hline Times prompted & - & - & - & $\begin{array}{c}9.22 \\
(10.33)\end{array}$ & - \\
\hline Times initiated & - & $\begin{array}{l}- \\
- \\
-\end{array}$ & - & $\begin{array}{c}1.93 \\
(3.55)\end{array}$ & $\begin{array}{l}- \\
- \\
-\end{array}$ \\
\hline Average duration (min) & - & - & - & $\begin{array}{c}38.24 \\
(15.83)\end{array}$ & $\begin{array}{l}- \\
- \\
-\end{array}$ \\
\hline Observations & 170 & 160 & 166 & 161 & 657 \\
\hline
\end{tabular}

Notes: Standard deviations in parentheses. Summaries for hours of productive, unproductive, and course time exclude days for which the software was inactive. 


\subsubsection{Commitment Device}

In addition to having access to time-use summary reports, students assigned to the commitment device treatment were able to set a limit on distracting Internet time each day. To maximize the potential impact of the treatment, students were initially assigned a limit that corresponded to the goal stated in the pre-study survey. This approach leverages the tendency people have to stay with a default choice (e.g Madrian and Shea, 2001). Participants in this treatment group were sent a daily email at 6:45 a.m. that informed them of their current limit and asked them whether they wished to reset their limit (see Appendix Figure A.1.2 for an example of how students set their distracting limit). ${ }^{24}$ Once students exceeded their set limit, distracting websites were blocked (blocked screen shown in Appendix Figure A.1.3). After exceeding their limit, students were only able to unblock websites on a site-by-site basis and needed to indicate a reason for unblocking each site.

The commitment device was designed to address issues of present-biased preferences by allowing students to make future distracting computer use more costly. However, the commitment device may address other behavioral issues including limited memory by providing students with a daily email and limited willpower by blocking distracting websites. ${ }^{25}$ Column 2 of Table 1.1 summarizes student use of the commitment software. Over the duration of the study, students in the commitment device treatment set an average limit of 2.7 hours and students only exceeded this limit an average of four times during the study. Although students had the flexibility to change their distracting limit on a daily basis, students rarely did - only changing their limit an average of one time during the study.

\footnotetext{
${ }^{24}$ Time of email was according to the timezone registered by the participant's IP address.

${ }^{25}$ See Appendix B for more detailed predictions about the commitment device treatment.
} 


\subsubsection{Reminder}

Students in the reminder treatment triggered an onscreen reminder after each half-hour they spent on distracting websites (see Appendix Figure A.1.4 for example). ${ }^{26}$ This reminder reported the amount of time the student spent on distracting websites and provided students with a link to the course website. The purpose of this design was to deliver a reminder that was salient, unlikely to disrupt productive activity, and most likely to occur when the student had time available to work on the course. By providing targeted reminders to students, the reminder treatment has the potential to address issues of limited memory. ${ }^{27}$ Table 1.1 indicates that students in this treatment received reminders on a regular basis, receiving an average of 48 reminders during the course.

\subsubsection{Focused Study}

Students assigned to the focusing treatment were prompted with an option to block websites for 15,30 , or 60 minutes when they went to the course website (see Appendix Figure A.1.5 for example). This focus study prompt was delivered to students at most once per day and occurred the first time a student went to the course website each day. In contrast to the commitment device, which allows students to block distracting sites in the future, the focus study tool only allows students to immediately block distracting sites. Additionally, students were required to visit the course website in order to interact with the focus study tool. As a result, the focus tool may address issues of limited willpower, but is unlikely to address issues of present-bias preferences or limited memory. ${ }^{28}$ Table 1.1 shows that students in the focusing treatment were prompted to start a focused study session 9.2 times during the course, and chose to initiate a focused study session an average of 1.9 times during the

\footnotetext{
${ }^{26}$ The reminder opened in a new web browser window that occupied a significant portion of the student's screen.

${ }^{27}$ See Appendix B for a more detailed predictions regarding the reminder treatment.

${ }^{28}$ See appendix B for a more comprehensive discussion of predictions concerning the focus study treatment.
} 
course. When the students did initiate a focused study session, the average duration was 38 minutes.

\section{Results}

\subsection{Impact on Aggregate Course Outcomes}

In this section I test whether the commitment device, reminder, and focusing tools impact student effort and performance. Measures of effort include number of homework assignments submitted and hours logged on the course website, while measures of student performance include standardized course score (z-score) and course completion. ${ }^{29}$ Randomization allows unbiased treatment effects to be estimated with ordinary least squares (OLS). To evaluate the impact of treatments on student outcomes, I estimate:

$$
y_{i}=a+\sum_{j=1}^{3} \gamma_{j} T_{i j}+\nu \mathbf{X}_{i}+\epsilon_{i}
$$

where $y_{i}$ is a measure of effort or academic performance for individual $i ; T_{i j}$ is an indicator of the treatment assignment for individual $i$; and $\mathbf{X}_{i}$ is a vector of student characteristics collected in the pre-study survey including age, education, income, location, course goals and objectives, previous course experience, and reported measures of self-control. ${ }^{30}$

\footnotetext{
${ }^{29}$ Time spent on course is calculated by Stanford from web activity logs. This calculation is likely an over estimate of actual course time as Stanford counts all time between course events that are no longer than 30 minutes as time spent on course. The last event in any session is counted as lasting for 500 seconds. Z-scores were constructed using the data from all students enrolled in the MOOC. Completion is defined by meeting the $60 \%$ score threshold for earning a certificate of completion.

${ }^{30}$ The full vector of control variables includes age $e^{2}$ and all variables listed in Appendix Table A.1.1.
} 
Richard W. Patterson

Table 2: Impact of Treatments on Course Outcomes

\begin{tabular}{lcccc}
\hline \hline & $\begin{array}{c}\text { Course Effort } \\
\text { (Hours) }\end{array}$ & $\begin{array}{c}\text { Homework } \\
\text { Submitted }\end{array}$ & $\begin{array}{c}\text { Course Grade } \\
\text { (Z-score) }\end{array}$ & $\begin{array}{c}\text { Course } \\
\text { Completion }\end{array}$ \\
\hline Commitment device & $5.491^{*}$ & $0.909^{* *}$ & $0.291^{* *}$ & $0.107^{* *}$ \\
Reminder & $(3.085)$ & $(0.403)$ & $(0.148)$ & $(0.0497)$ \\
Focused study & -3.339 & 0.267 & 0.0109 & 0.0108 \\
& $(2.597)$ & $(0.415)$ & $(0.150)$ & $(0.0503)$ \\
Dep var mean & 0.848 & 0.577 & 0.0966 & 0.0135 \\
Demographics & $(2.826)$ & $(0.412)$ & $(0.149)$ & $(0.0498)$ \\
Course variables & 22.38 & 3.730 & 0.711 & 0.289 \\
Self-control variables & $\mathrm{y}$ & $\mathrm{y}$ & $\mathrm{y}$ & $\mathrm{y}$ \\
Observations & $\mathrm{y}$ & $\mathrm{y}$ & $\mathrm{y}$ & $\mathrm{y}$ \\
R-squared & 657 & 657 & 657 & $\mathrm{y}$ \\
\hline
\end{tabular}

*** $\mathrm{p}<0.01,{ }^{* *} \mathrm{p}<0.05, * \mathrm{p}<0.1$. Robust standard errors in parentheses. Demographic variables include gender, age, age ${ }^{2}$, education, income, continent, and indicators for missing age and income variables. Course variables include course goals: finish for certificate, finish at own pace, complete some assignments, or watch some videos, reasons taking the course: general interest, relevant to school/work/research, career change, fun, try online course, improve English, type of computer: personal laptop, personal desktop, work computer, previous online courses started, previous online courses finished, previous statistics courses taken, interest level in course, expected course hours, and importance of finishing course. Self-control variables include distracting time goal, desired change in distracting time, self reported difficulty breaking habits, distractibility, ability to resist temptation, level of self-discipline, and take actions that are regretted in long run.

The results of the estimation of equation 1 are presented in Table 1.2. ${ }^{31}$ First I estimate the impact of treatment assignment on the amount of time students spend on the course website. This measure of effort has the advantage of incorporating all course activities, not just those that are graded. Column 1 of Table 1.2 shows that the commitment device increased time spent on the course website by 5.5 hours, or $24 \%$, relative to the control (significant at the $10 \%$ level). Students in the commitment device treatment also spent significantly more time on the course website than students in the reminder treatment $(8.8$ hours, significant at the $1 \%$ level) and focusing treatment (4.6 hours, significant at the $10 \%$

\footnotetext{
${ }^{31}$ Appendix Table A.1.3 reports estimates that include participants who join the study after the first week. The specifications estimated in Appendix Table A.1.3 are consistent with those presented in Table 1.2.
} 
Richard W. Patterson level). Although imprecisely estimated, neither the reminder treatment nor the focusing treatment led to statistically significant changes in time spent on the course.

One potential weakness of using course time as a measure of effort is that it cannot account for any impact the treatments have on how effectively students spend their time. If the treatments lead students to change how efficiently they use their time when working on the course, then the estimated impact the treatments may be biased. Homework submissions provide an additional measure of course effort that is not subject to this potential bias of the course time measure. Column 2 of Table 1.2 presents estimates of the impact of the treatments on the number of homework assignments submitted. Consistent with the course time results, I find that the commitment device has a significant impact on homework submissions, increasing the number of homework assignments submitted by 0.91 -an increase of $27 \%$ relative to the control (significant at the $5 \%$ level). While the impact of the reminder and focusing treatments on homework submission patterns are smaller than those estimated for the commitment device and statistically indistinguishable from the control, estimated effects for both groups are positive ( 0.27 and 0.58 additional homework assignments, respectively) and large effects cannot be ruled out for these groups.

The impact of the treatments on student academic outcomes corresponds closely with those estimated for effort. Column 3 of Table 1.2 shows that the commitment device improves total course performance by 0.29 standard deviations, which is significant at the $5 \%$ level. To provide some context, this is roughly the same difference in course performance observed between students with Ph.D.s or M.D.s and students with bachelor's degrees (0.28 standard deviations, significant at the $1 \%$ level). In contrast, the reminder treatment has essentially no measured influence on course performance (an increase of 0.01 standard deviations) and the estimated impact of the focusing treatment is one-third the size of the commitment device (0.10 standard deviations) and statistically indistinguishable from the control. 
Richard W. Patterson

Finally, column 4 of Table 1.2 indicates that the commitment device has a large impact on course completion, increasing completion rates by $40 \%$ or 11 percentage points (significant at the $5 \%$ level). The reminder and focusing treatments, however, have no measurable impact on completion, with point estimates that are close to zero (both associated with 1 percentage point increase in completion) and that are significantly smaller than the estimated impact of the commitment device (both significant at the $10 \%$ level).

In total, the reported results in Table 1.2 indicate that the commitment treatment has a significant impact on both course effort and outcomes. These results are consistent with students procrastinating, or exhibiting present-biased preferences. In contrast, neither the reminder nor the focusing treatment have a significant impact on either student effort or performance. Importantly, the effects of the reminder and focus tools are imprecisely estimated and neither their efficacy nor the potential roles of limited memory and limited willpower can be ruled out. Nevertheless, the results do indicate that the commitment device is more effective than the other treatments in improving course outcomes.

\subsection{Timing of Treatment Effects}

How the software tools impact student effort over time has important implications for how to interpret and generalize the results of this study. If the differences in student effort between treatments and control are present throughout the duration of the course, then this suggests that treatments may be effective in addressing long-run behavioral issues. However, if differences in effort between treatment and controls are only observed in the first few weeks of the course, then the impact of the software tools may not generate persistent long-run effects for students. Because student interaction with the treatment software is observed, I am able to examine how patterns in software use compare to trends in course effort. To 
Richard W. Patterson

investigate how the software treatments impact course effort over time I estimate:

$$
y_{i t}=a+\sum_{j=1}^{3} \gamma_{j} T_{i j}+\sum_{t=2}^{9} \theta_{t} \text { wee }_{i t}+, \sum_{j=1}^{3} \sum_{t=2}^{9} \lambda_{j t} T_{i j} * \text { week }_{i t}+\nu \mathbf{X}_{i}+\epsilon_{i t}
$$

where $y_{i t}$ is a measure of effort for individual $i$ in week $t ; T_{i j}$ is an indicator of individual treatment assignment; week $k_{i t}$ is an indicator for the week in which the academic outcome was observed for individual $i$; $T_{i j} * w_{e} k_{i t}$ is the interaction between treatment assignment and the week of the course, and other variables are as previously specified. Standard errors are clustered at the individual level. Results of this estimation for time spent on course and homework submissions are graphically presented in Figures 1.1 and 1.2, respectively. The points in Figures 1.1-1.2 represent estimated differences in course hours and homework submissions between treatments and control in each week $\left(\gamma_{j}+\lambda_{j t}\right)$ with bounds indicating $95 \%$ confidence intervals. To interpret the results of these estimations it is important to note two things - first, the weekly differences between each treatment and control $\left(\gamma_{j}+\lambda_{j t}\right)$ capture both the persistent effects of previous treatment and contemporaneous effects of the current treatment. Second, students were able to work ahead in the course and the extent to which treatments lead students to work ahead leads to larger differences in early weeks and smaller differences in later weeks than would have otherwise been observed. Nevertheless, these figures do provide insight into when in the course the differences in effort are observed.

While the estimates are somewhat imprecise, Figures 1.1 and 1.2 show three interesting patterns. First, differences in effort between the commitment and control group, in terms of hours of course time and homework submissions, are largest at the beginning of the course but remain positive and significant for the majority of the course. Second, the reminder treatment appears to have no positive impact on course outcomes at any point during the study. Third and finally, the differences in effort between the focusing treatment and control are significant at the beginning of the course but then dissipate after the first two to three 
Figure 1: Effort (in Hours), by Week
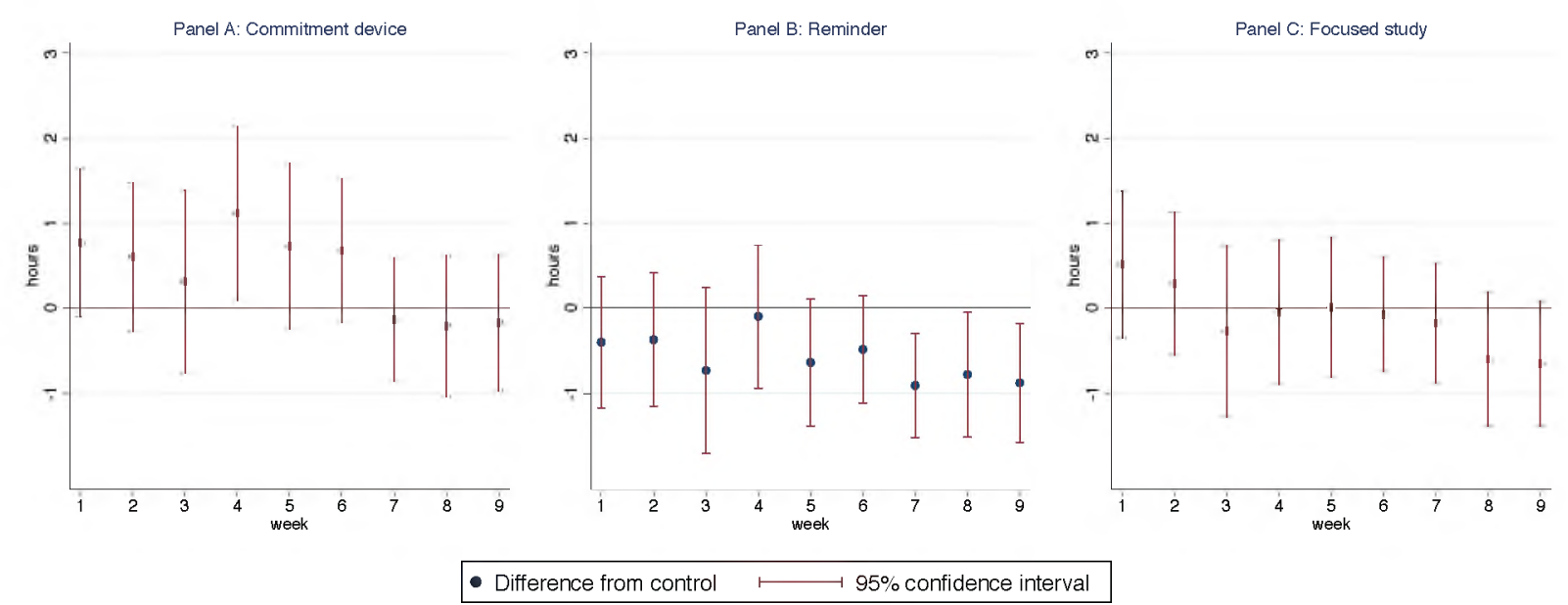

Panels A, B, and $\mathrm{C}$ show estimated differences in weekly hours spent on course between treatment and control $\left(\gamma_{j}+\lambda_{j t}\right.$ in equation 2) for commitment device, reminder, and focusing treatments, respectively. Bounds represent $95 \%$ confidence intervals. Estimates are generated from an OLS panel estimation with controls for demographic, course, and self-control variables. Standard errors are clustered at the individual level.

weeks.

Figure 2: Homework Assignments Submitted, by Week
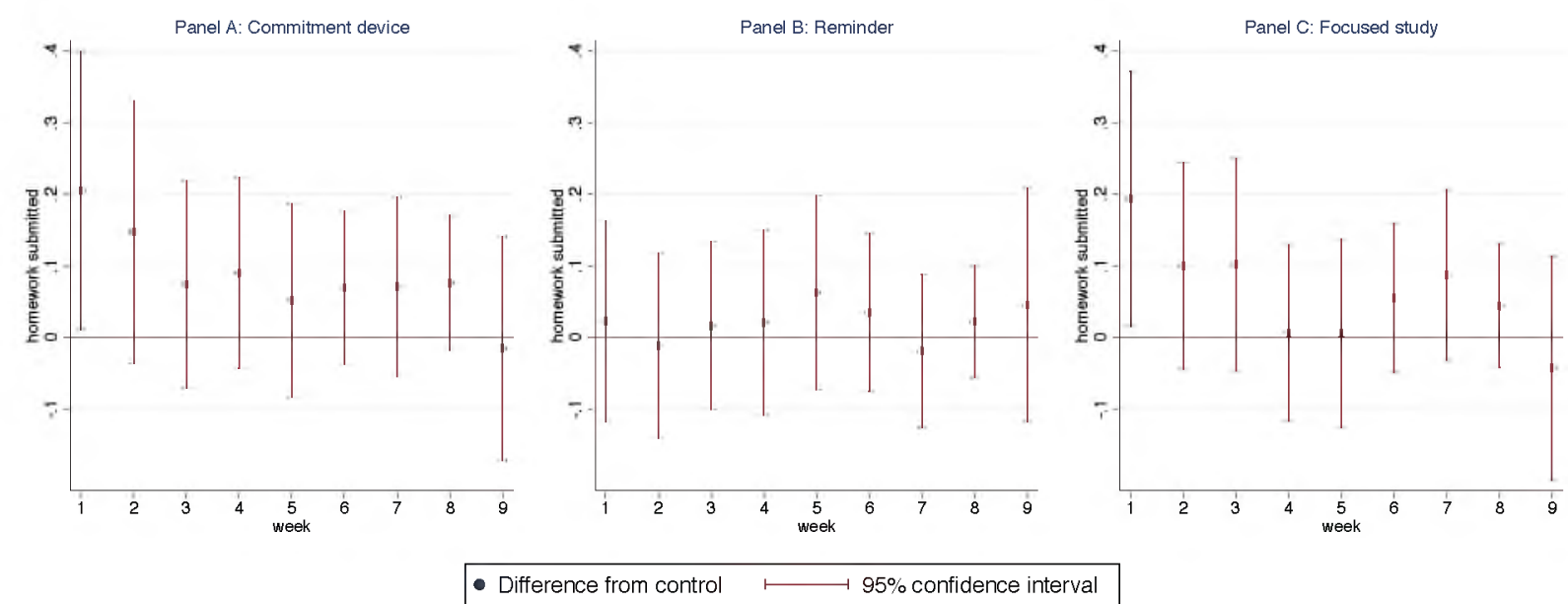

Panels A, B, and $\mathrm{C}$ show estimated differences in weekly homework submissions between treatment and control $\left(\gamma_{j}+\lambda_{j t}\right.$ in equation 2) for commitment device, reminder, and focusing treatments, respectively. Bounds represent $95 \%$ confidence intervals. Estimates are generated from an OLS panel estimation with controls for demographic, course, and self-control variables. Standard errors are clustered at the individual level. 
Richard W. Patterson

As previously mentioned, the ability of students to work ahead in the course makes it difficult to make inference about the persistence of treatment effect. One way to identify an upper bound for the persistence of the treatment effects on homework submissions is to estimate how treatments affect on-time submission of each weekly assignment. ${ }^{32}$ I estimate the impact of treatment on whether each weekly assignment was submitted using the same estimation strategy outlined in equation 2 , except $y_{i t}$ is now an indicator for whether the assignment due in week $t$ was submitted by week $t$. Results of this estimation are presented in Figure 1.3. This plot shows similar patterns to Figure 1.2. The commitment device increases the probability of each week's homework submission by approximately $10 \%$, the reminder has no significant impact on homework submissions at any time during the study, and the focusing treatment significantly increases the probability that the first few weeks' homework assignments are submitted, but this difference declines over time.

Figure 3: On-time Homework Submissions, by Week
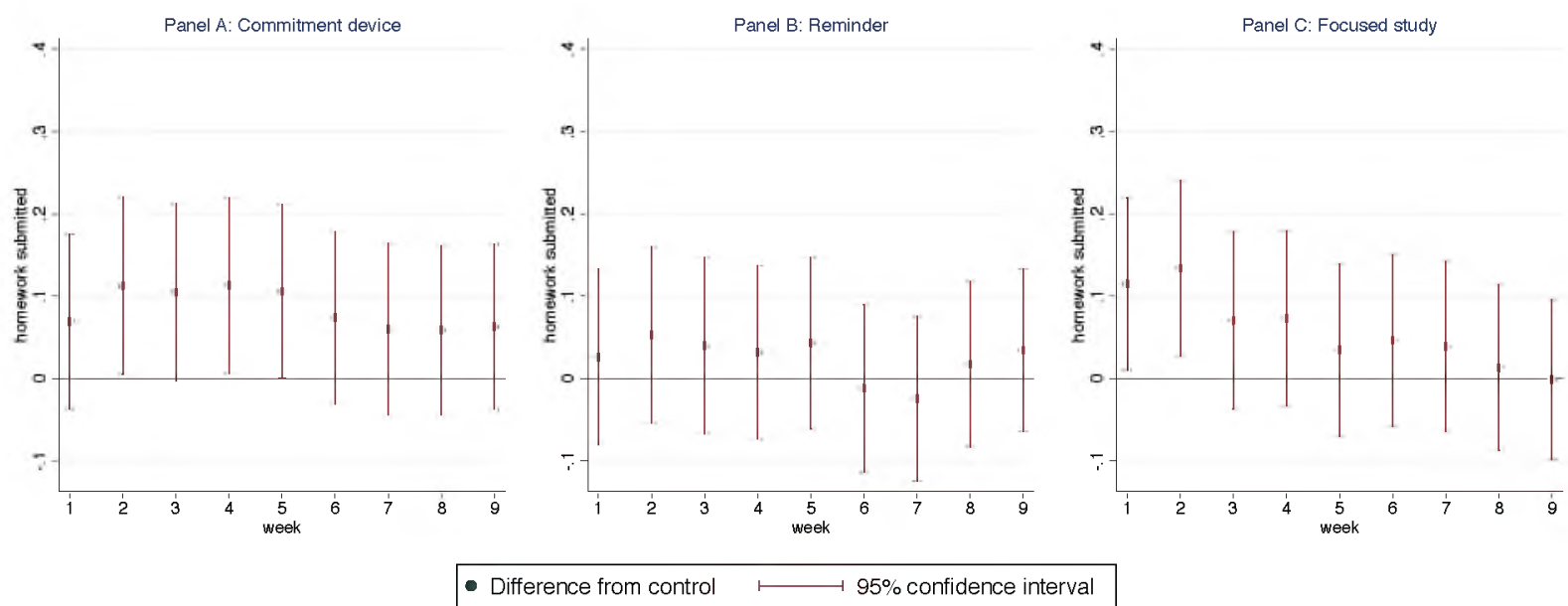

Panels A, B, and C show estimated differences in whether students submitted weekly homework assignments on-time between treatment and control $\left(\gamma_{j}+\lambda_{j t}\right.$ in equation 2) for commitment device, reminder, and focusing treatments, respectively. Bounds represent 95\% confidence intervals. Estimates are generated from an OLS panel estimation with controls for demographic, course, and self-control variables. Standard errors are clustered at the individual level.

\footnotetext{
${ }^{32}$ Because I cannot assign course time to particular assignments, I am unable to perform a similar exercise for hours spent on course.
} 


\subsection{Timing of Software Use}

Richard W. Patterson

How students use software over time provides additional context for the treatment effects reported in Figures 1.1-1.3. Panel A of Figure 1.4 reports trends in whether software was installed in each week, and shows that students in all treatment groups, including the control, are significantly less likely to have software installed as the course progresses. ${ }^{33}$ Given the significant differences in software experience by treatment, it is somewhat surprising that there are not large differences in software use by treatment (reported in Panels B, C, and D of Figure 1.4). Students in the commitment device treatment are $8 \%$ less likely to be running the software relative to students in the control (significant at the $10 \%$ level), and students in the reminder and focusing treatments do not have statistically significant differences in software use from the control.

In addition to being less likely to have software installed over time, students in the commitment device and focusing treatments who continue to use the software become less likely to utilize treatment components of their software as the course progresses. Appendix Figure A.1.6, which reports patterns of student interaction with the commitment software, ${ }^{34}$ illustrates how students make their commitments significantly less restrictive over the duration of the course. By the end of the course, students allow themselves nearly twice as much distracting time and reach their limit less than half as often than in the first week. Appendix Figure A.1.7 shows a similar drop in software engagement for students in the focusing treatment. Encouragingly, the patterns in software utilization match the patterns of effort observed in Figures 1.1 and 1.2. This consistency provides additional evidence that the differences in outcomes between treatment and control are, indeed, driven by the software

\footnotetext{
${ }^{33} \mathrm{I}$ am unable to distinguish between students who have actually uninstalled software, have turned off software, or have not used computers in a given week. However, if the student's computer does not send any time use data to the server then the student can have no interaction with the study software during the week. I therefore define software being installed as the server receiving any time-use data from the student's computer during the week.

${ }^{34}$ These patterns are reported for students who run the software in each week.
} 
Figure 4: Software Installed, by Week
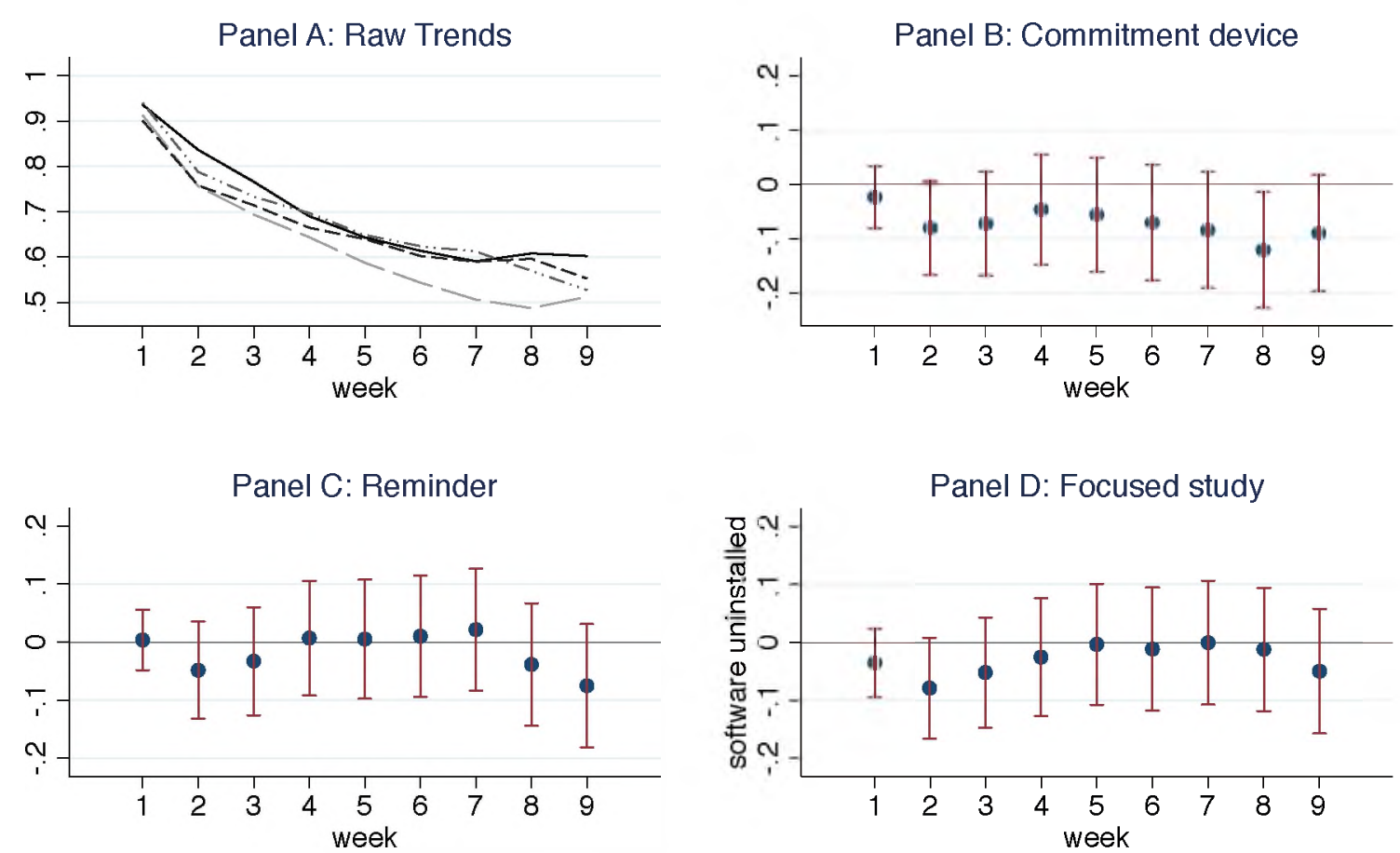

Panel D: Focused study
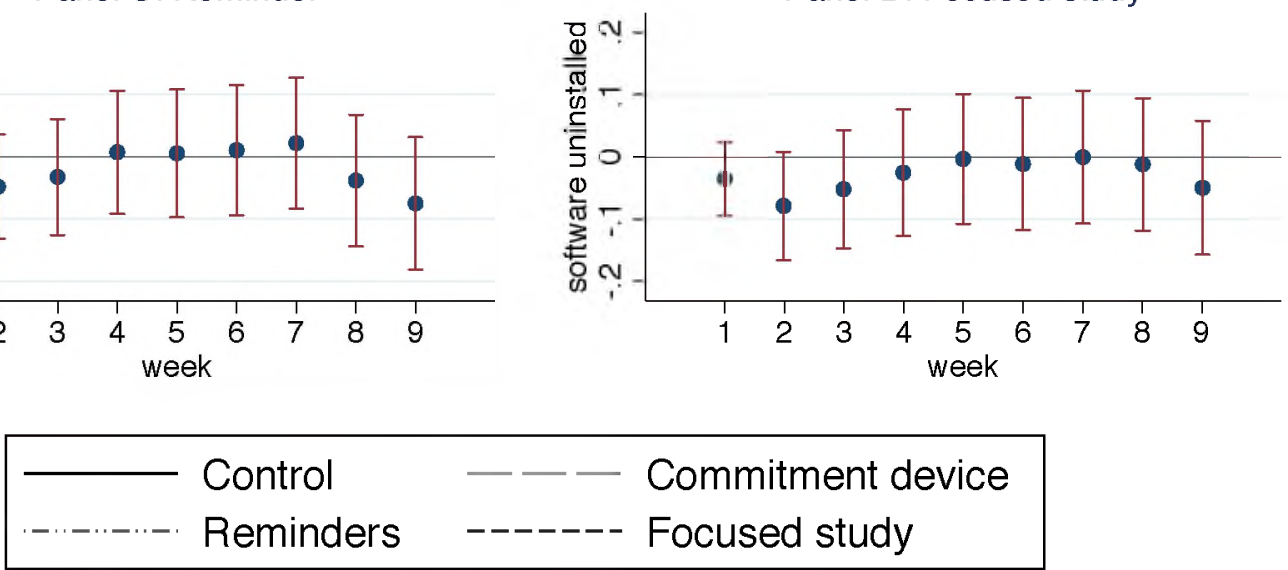

Panel A presents the raw trends for whether software was installed by treatment and week. Panels B, C, and D show coefficient estimates and $95 \%$ confidence intervals for commitment device, reminder, and focusing treatment effects, respectively. Estimated coefficients and confidence intervals are generated from an OLS panel estimation which included treatment, week, and treatment $*$ week indicators along with demographic, course, and self-control variables. Standard errors are clustered at the individual level.

treatments.

\subsection{Heterogeneous Treatment Effects}

To provide evidence on the behavioral mechanisms and to inform the generalizability of the results, I test whether responses to the treatments vary by student characteristics. In particular, I test whether treatment effects are larger for students with a strong desire to 
Richard W. Patterson

finish coursework on-time and whether treatment effects vary by how well students are predicted to do in the course, given characteristics that are measured prior to the course. ${ }^{35}$

\subsubsection{Course Goals}

While this study focuses on the impact of the treatments on academic outcomes like assignment submission, course performance, and course completion, it is not important to all MOOC students to submit assignments or complete the course. If the treatments are most effective for students intending to finish the course, then the treatments are likely to be welltargeted and improve well-being. If, however, the treatments are most effective for students who never intended to complete the course, the welfare implications are moreambiguous. In the pre-study survey, students were asked how important it was to complete all the course quizzes and tests on-time. I create an indicator for students responding "very important" or "extremely important" and test whether these students are more likely to respond to the treatments. ${ }^{36}$ To test whether response to treatment varies by student goals, I estimate:

$$
y_{i t}=a+\text { ggoal }_{i}+\sum_{j=1}^{3} \gamma_{j} T_{i j}+\sum_{j=1}^{3} \lambda_{j} T_{i j} * \text { goal }_{i}+\nu \mathbf{X}_{i}+\epsilon_{i}
$$

where goal $_{i}$ is an indicator for whether student $i$ strongly desired to finish the course, $T_{i j} *$ goal $_{i}$ is the interaction between treatment assignment and desire to finish course, and all other variables are as previously specified. Table 1.3 reports the result of this analysis. Although the estimates are imprecise, the results suggest that the response to the commitment device is driven by students for whom finishing the course material on-time is either very or extremely

\footnotetext{
${ }^{35}$ I also examine whether treatment effects are larger for students who are more likely to have self-control problems given their level of agreement with statements such as: "I do things that feel good in the moment but regret later on" and "Im good at resisting temptation." Estimates for this analysis are imprecise and uninformative, so are not included in the main body of the paper. However, results of this analysis are reported in Appendix Table A.1.4.

${ }^{36}$ Students had 5 options to respond to this question including: (1) not important at all; (2) not very important; (3) moderately important; (4) very important; and (5) extremely important.
} 
Richard W. Patterson important. Point estimates of the interaction between the commitment treatment and goal $\left(\lambda_{1}\right)$ are large for effort (9.9 hours, significant at the $10 \%$ level), homework submissions (1.1 assignments), aggregate course performance (0.46 standard deviations), and completion (14 percentage points), while the estimates of the commitment device's impact on the students for which completion is not very important are small or even negative for effort (-2.1 hours), homework (0.1 assignments), z-scores (0.04 standard deviations), and completion (1 percentage point). The estimated effects of the reminder and focusing treatments are even less precisely measured, but show similar patterns, with positive, but statistically insignificant, reminder $*$ goal and focus $*$ goal interaction coefficients. 
Richard W. Patterson

Table 3: Heterogeneous Treatment Effects, Goals

\begin{tabular}{|c|c|c|c|c|}
\hline & $\begin{array}{l}\text { Course Effort } \\
\text { (Hours) }\end{array}$ & $\begin{array}{l}\text { Homework } \\
\text { Submitted }\end{array}$ & $\begin{array}{c}\text { Course Grade } \\
\text { (Z-score) }\end{array}$ & $\begin{array}{c}\text { Course } \\
\text { Completion }\end{array}$ \\
\hline Commitment*Importance & $\begin{array}{l}9.898^{*} \\
(5.813)\end{array}$ & $\begin{array}{c}1.068 \\
(0.843)\end{array}$ & $\begin{array}{c}0.457 \\
(0.306)\end{array}$ & $\begin{array}{c}0.136 \\
(0.103)\end{array}$ \\
\hline Reminder $*$ Importance & $\begin{array}{l}-1.659 \\
(5.010)\end{array}$ & $\begin{array}{c}0.804 \\
(0.847)\end{array}$ & $\begin{array}{c}0.311 \\
(0.300)\end{array}$ & $\begin{array}{c}0.115 \\
(0.0995)\end{array}$ \\
\hline Focus $*$ Importance & $\begin{array}{c}0.142 \\
(5.600)\end{array}$ & $\begin{array}{l}0.0808 \\
(0.840)\end{array}$ & $\begin{array}{c}0.194 \\
(0.297)\end{array}$ & $\begin{array}{c}0.0589 \\
(0.0995)\end{array}$ \\
\hline Commitment device & $\begin{array}{l}-2.172 \\
(3.820)\end{array}$ & $\begin{array}{r}0.0793 \\
(0.666)\end{array}$ & $\begin{array}{r}-0.0442 \\
(0.234)\end{array}$ & $\begin{array}{l}0.00763 \\
(0.0788)\end{array}$ \\
\hline Reminder & $\begin{array}{l}-3.472 \\
(3.311)\end{array}$ & $\begin{array}{l}-0.263 \\
(0.634)\end{array}$ & $\begin{array}{l}-0.194 \\
(0.221)\end{array}$ & $\begin{array}{l}-0.0639 \\
(0.0703)\end{array}$ \\
\hline Focused study & $\begin{array}{c}0.306 \\
(3.721)\end{array}$ & $\begin{array}{c}0.505 \\
(0.637)\end{array}$ & $\begin{array}{r}-0.0369 \\
(0.220)\end{array}$ & $\begin{array}{l}-0.0294 \\
(0.0729)\end{array}$ \\
\hline Important to complete & $\begin{array}{l}9.277^{* *} \\
(4.037)\end{array}$ & $\begin{array}{l}0.994^{*} \\
(0.594)\end{array}$ & $\begin{array}{c}0.233 \\
(0.217)\end{array}$ & $\begin{array}{c}0.0689 \\
(0.0704)\end{array}$ \\
\hline Dep var mean & 22.38 & 3.730 & 0.289 & 0.711 \\
\hline Demographic variables & $\mathrm{y}$ & $\mathrm{y}$ & $\mathrm{y}$ & $\mathrm{y}$ \\
\hline Course variables & $\mathrm{y}$ & $\mathrm{y}$ & $\mathrm{y}$ & $\mathrm{y}$ \\
\hline Self-control variables & $\mathrm{y}$ & $\mathrm{y}$ & $\mathrm{y}$ & $\mathrm{y}$ \\
\hline Observations & 657 & 657 & 657 & 657 \\
\hline R-squared & 0.163 & 0.132 & 0.129 & 0.116 \\
\hline $\begin{array}{l}* * * \mathrm{p}<0.01, * * \mathrm{p}<0.05, * \mathrm{p}<0 \\
\text { variable is an indicator for whet } \\
\text { finish assignments and tests on- } \\
\text { education, income, continent, an } \\
\text { include type of computer: pers } \\
\text { started, previous online courses } \\
\text { include distracting time goal, de } \\
\text { distractibility, ability to resist te } \\
\text { long run. }\end{array}$ & $\begin{array}{l}\text { Robust standa } \\
\text { students indice } \\
\text { ne for credit. D } \\
\text { indicators for mi } \\
\text { al laptop, person } \\
\text { ished, and previo } \\
\text { ed change in dist } \\
\text { ptation, level of }\end{array}$ & $\begin{array}{l}\text { errors in p } \\
\text { that it is } \mathrm{e} \\
\text { mographic } \\
\text { ing age and } \\
\text { desktop, wo } \\
\text { statistics co } \\
\text { cting time, s } \\
\text { f-discipline, }\end{array}$ & $\begin{array}{l}\text { ntheses. "Import } \\
\text { er very or extren } \\
\text { riables include g } \\
\text { ome variables. C } \\
\text { computer, previo } \\
\text { ses taken. Self-ce } \\
\text { reported difficulty } \\
\text { take actions tha }\end{array}$ & $\begin{array}{l}\text { to complete" } \\
\text { y important to } \\
\text { der, age, age }{ }^{2} \\
\text { irse variables } \\
\text { online courses } \\
\text { trol variables } \\
\text { reaking habits } \\
\text { re regretted in }\end{array}$ \\
\hline
\end{tabular}

\subsubsection{Predicted Outcomes}

The above heterogeneity results describe how course objectives interact with treatments. Also of interest is how the treatments impact those expected to do better or worse in the course, given their observable pre-study characteristics. To test whether expected course performance impacted the magnitude of the treatment response, I implement a split-sample 
Richard W. Patterson endogenous stratification estimator as is outlined by Abadie et al. (2013). This estimation strategy uses students in the control group to generate predicted outcomes for students in all treatment groups (including the control) and then estimates the treatment effects within quantiles of predicted outcomes. To overcome the bias introduced by overfitting issues that arise when a student's characteristics are used to predict their own outcomes, ${ }^{37}$ this estimation strategy takes the following steps: (1) randomly select half the control group and use this group to estimate predicted outcomes with observable pre-study characteristics for the remainder of the students; (2) bin students into predicted outcome quantiles (excluding the students used to estimate predicted outcomes); (3) estimate treatment effects within quantile bins and store estimates; (4) iterate steps 1-3 multiple times; and (5) bootstrap standard errors. ${ }^{38}$

\footnotetext{
${ }^{37}$ In finite samples, predicted values for observations with large positive or negative error terms tend to be overfitted. Because of overfitting, students in the control group who have poor outcomes driven by unobservable characteristics are more likely to have poor predicted outcomes than students in the treatment group who also have poor outcomes due to unobservable characteristics. Symmetrically, students in the control group with strong outcomes due to unobservable characteristics are more likely than similar students in the treatment group to have strong predicted outcomes. As a result, estimates that include control students' own characteristics are biased towards finding positive treatment effects for weak students and negative treatment effects for strong students.

${ }^{38}$ Estimates reported in this paper are generated by 200 sample splits and 500 bootstrap repetitions. See Abadie et al. (2013) for more details.
} 
Richard W. Patterson

Table 4: Heterogeneous Treatment Effects, Predicted Outcomes

\begin{tabular}{|c|c|c|c|c|c|}
\hline \multirow{3}{*}{ Course Effort (Hours) } & \multicolumn{5}{|c|}{ Quintile of Predicted Outcome } \\
\hline & (1) & (2) & (3) & (4) & (5) \\
\hline & & & & & \\
\hline \multirow[t]{2}{*}{ Commitment device } & -2.031 & 0.272 & 4.958 & 6.512 & 9.362 \\
\hline & $(3.835)$ & $(3.159)$ & $(3.627)$ & $(4.633)$ & $(6.889)$ \\
\hline \multirow[t]{2}{*}{ Reminder } & -4.223 & $-5.178^{* *}$ & $-6.265^{* *}$ & $-8.054^{* * * * *}$ & -2.609 \\
\hline & $(3.625)$ & $(2.482)$ & $(2.598)$ & $(2.994)$ & $(3.797)$ \\
\hline \multirow[t]{2}{*}{ Focused study } & -0.618 & -1.701 & -1.736 & -2.131 & -0.003 \\
\hline & $(3.809)$ & $(2.956)$ & $(3.464)$ & $(4.262)$ & $(6.727)$ \\
\hline \multicolumn{6}{|l|}{ Homework Submitted } \\
\hline \multirow{2}{*}{ Commitment device } & -0.161 & 0.034 & 0.723 & $1.126^{*}$ & $1.841^{* * * *}$ \\
\hline & $(0.643)$ & $(0.476)$ & $(0.571)$ & $(0.630)$ & $(0.640)$ \\
\hline \multirow[t]{2}{*}{ Reminder } & -0.005 & -0.037 & 0.060 & 0.308 & 0.784 \\
\hline & $(0.625)$ & $(0.452)$ & $(0.559)$ & $(0.600)$ & $(0.649)$ \\
\hline \multirow[t]{2}{*}{ Focused study } & 0.089 & -0.075 & 0.322 & 0.848 & $1.345^{* *}$ \\
\hline & $(0.590)$ & $(0.457)$ & $(0.576)$ & $(0.621)$ & $(0.678)$ \\
\hline \multicolumn{6}{|l|}{ Course Grade (Z-score) } \\
\hline \multirow[t]{2}{*}{ Commitment device } & -0.140 & 0.081 & 0.259 & 0.354 & $0.570 * *$ \\
\hline & $(0.220)$ & $(0.163)$ & $(0.194)$ & $(0.254)$ & $(0.269)$ \\
\hline \multirow[t]{2}{*}{ Reminder } & -0.068 & -0.132 & -0.021 & -0.031 & 0.102 \\
\hline & $(0.215)$ & $(0.153)$ & $(0.185)$ & $(0.233)$ & $(0.256)$ \\
\hline \multirow[t]{2}{*}{ Focused study } & -0.135 & -0.104 & 0.014 & 0.178 & 0.303 \\
\hline & $(0.208)$ & $(0.154)$ & $(0.192)$ & $(0.249)$ & $(0.272)$ \\
\hline
\end{tabular}

*** $\mathrm{p}<0.01, * * \mathrm{p}<0.05,{ }^{*} \mathrm{p}<0.1$. Bootstrap standard errors in parentheses. Split-sample endogenous stratification estimates reported (Abadie et al., 2013). Estimates are generated with 200 sample splits and 500 bootstrap repetitions. Variables used to construct predicted values include demographic, course, and self control variables. Demographic variables include gender, age, age ${ }^{2}$, education, income, continent, and indicators for missing age and income variables. Course variables include course goals: finish for certificate, finish at own pace, complete some assignments, or watch some videos, reasons taking the course: general interest, relevant to school/work/research, career change, fun, try online course, improve English, type of computer: personal laptop, personal desktop, work computer, previous online courses started, previous online courses finished, previous statistics courses taken, interest level in course, expected course hours, and importance of finishing course. Self-control variables include distracting time goal, desired change in distracting time, self reported difficulty breaking habits, distractibility, ability to resist temptation, level of self-discipline, and take actions that are regretted in long run.

I use the above strategy to estimate the impact of the treatments on effort, homework submissions, and points scored and present the results of this estimation in Table 1.4. These results suggest that the impact of the commitment device has a strong positive correlation with predicted outcomes. For each outcome course hours, homework, and grades - the 
Richard W. Patterson estimated impact of the commitment device increases with the quintile of predicted outcome. Students in the reminder and focus study treatment also exhibit similar patterns but the correlation is smaller and less consistent. These results suggest that the commitment device, and, to a lesser extent, the reminder an focus study treatments were most helpful to students who were likely to succeed in the MOOC in the first place.

\subsection{Post-Study Survey}

Following the course, students were incentivized with a $\$ 7$ Amazon.com gift card to complete a post-study survey. This survey asked students a number of questions about how the software impacted their computer use and experience in the course. The results of these survey questions are reported in Table 1.5 . Only $52 \%$ of study participants completed the post-study survey. Also, the first row in Table 1.5 indicates that survey response was not constant across treatment groups - a greater portion of students in the commitment device treatment responded to the survey than those in other treatments. Therefore, the results should be interpreted cautiously. Nevertheless, student responses do shed additional light on the potential mechanisms driving response to treatments. The most significant difference observed between treatment and control is that students in the commitment and reminder treatments much than those in the control group to report that the treatment made unproductive time less enjoyable. Students in the commitment and reminder treatments were $81 \%$ (23 percentage points, significant at the $1 \%$ level) and 61\% (17 percentage points, significant at the $5 \%$ level) more likely than students in the control treatment to state that the software made unproductive time less enjoyable, respectively. That students in the commitment device treatment found unproductive time less enjoyable suggests that the commitment device worked in the way it was intended - making spending time on unproductive websites more difficult or costly. Other differences were not statistically significant, but students in the commitment device treatment were most likely to report that the software increased the 
Richard W. Patterson

time they spent on the course and to report using the software to set course goals. The results of the post-study survey are consistent with students using the commitment device to address present-biased preferences - making distracting time more costly in order to increase the amount of time spent on coursework. ${ }^{39}$

Table 5: Post Study Survey Responses

\begin{tabular}{|c|c|c|c|c|}
\hline & Control & Commitment & Reminder & Focus \\
\hline Completed post survey & 0.465 & $0.650^{* *}$ & 0.482 & 0.503 \\
\hline Software increased thinking about course & 0.413 & 0.505 & 0.487 & 0.438 \\
\hline Software reduced distracting time & 0.413 & 0.485 & 0.526 & 0.354 \\
\hline Software increased time spent on course & 0.320 & 0.402 & 0.308 & 0.237 \\
\hline Software made unproductive time less enjoyable & 0.280 & 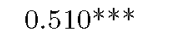 & $0.449^{* *}$ & 0.291 \\
\hline Software improved understanding of time use & 0.627 & 0.656 & 0.756 & 0.544 \\
\hline Used software to set course goals & 0.189 & 0.271 & 0.205 & 0.175 \\
\hline Used software to set general goals & 0.347 & 0.375 & 0.397 & $0.215^{*}$ \\
\hline Software was useful & 0.467 & 0.542 & 0.564 & 0.423 \\
\hline Observations & 170 & 160 & 166 & 161 \\
\hline
\end{tabular}

\section{Conclusion}

Low completion rates and poor student performance are among the most serious problems facing online education. This study tests whether computerized tools intended to address behavioral issues of present-biased preferences (commitment device), limited memory (reminder), and limited willpower (focus tool) increased course completion and improved student performance in a massive open online course. The primary finding in this paper is that the commitment device, which allows students to pre-commit to the amount of distracting

\footnotetext{
${ }^{39}$ One puzzle is that students in the reminder were also more likely than students in the control group to report that the software made distracting sites less enjoyable, yet experienced no measurable improvements in course outcomes. One possibility is that the choice is an important aspect of the software's impact. Students in the commitment were able to choose restrictiveness of their commitments whereas students in the reminder treatment had no choice for how the software would impact them. The aspect of choice in the commitment may have made it possible for students to better calibrate their interaction with the software, or lead students to have a more positive response to software disruptions.
} 
Richard W. Patterson time they spent each day, significantly improves course outcomes, including time spent on course, homework submissions, overall scores, and completion rates. The most striking of these results is that the commitment device increases course completion by $40 \%$ (11 percentage points). In contrast, I find that the reminder treatment, which provides students with a reminder after each half hour spent on distracting sites, has no measurable impact on course outcomes. I also find that the focusing treatment, which allows students to block distracting websites when they go to work on the course website, has generally positive estimated impacts on course performance, but these estimates are much smaller than those found for the commitment device, imprecisely estimated, and cannot be statistically distinguished from zero.

Although the estimated impacts of the commitment device on course outcomes are large and significant, the applicability of these findings to other settings depends on how the study sample and course environment relate to other populations and contexts. With a highly educated and internationally diverse sample that has an average age of around 30 , students in the study sample are not representative of online degree-seeking college students in the United States. However, study participants look remarkably similar to the other students enrolled in the Stanford statistics MOOC (see Appendix Table A.1.2) and to students observed in other MOOC settings (e.g. Banerjee and Duflo, 2014; Breslow et al., 2013; Waldrop, 2014), which observe student populations in which approximately $75 \%$ of students have a bachelor's degree or higher, $70 \%$ of students are from outside the United States, and the average age is close to 30 .

The heterogeneity analyses in this paper also provide insight into how the treatment effects are likely to apply in different contexts. First, I find that point estimates of the commitment device's impact are largest for students who indicate that finishing each assignment and test on-time is either very or extremely important. This result suggests that the treatments are likely to have the most impact in settings where online students have a strong 
Richard W. Patterson desire to finish their coursework. Second, I find that when demographic, course-related, and self-control variables are considered, students with the strongest predicted outcomes are most responsive to the commitment treatment, which indicates that, at least in this $\mathrm{MOOC}$ context, the strongest students are most likely to benefit from the commitment device. Although it is difficult to predict how the results of this study will generalize to online-degree seeking students in the United States, online-degree seeking students are likely to be subject to the same issues with distractions as are MOOC students. If online students generally struggle with issues of self-control related to distracting websites, then there may is potential for software tools like the commitment device to have a significant positive impact on academic outcomes. 


\section{References}

Richard W. Patterson

Abadie, Alberto, Matthew M Chingos, and Martin R West, "Endogenous Stratification in Randomized Experiments," 2013.

Allen, I Elaine and Jeff Seaman, Changing Course: Ten Years of Tracking Online Education in the United States., Babson Park, MA: Babson Survey Research Group, 2013.

Ariely, Dan and Klaus Wertenbroch, "Procrastination, Deadlines, and Performance: Self-Control by Precommitment," Psychological Science, May 2002, 13 (3), 219-224.

Ashraf, Nava, Dean Karlan, and Wesley Yin, "Tying Odysseus to the Mast: Evidence From a Commitment Savings Product in the Philippines," The Quarterly Journal of Economics, May 2006, 121 (2), 635-672.

Austin, Suzzane M, E Andrew Balas, Jane A Mitchell, and Bernard G Ewigman, "Effect of Physician Reminders on Preventive Care: Meta-Analysis of Randomized Clinical Trials.," in "Proceedings of the annual symposium on computer application in medical care" American Medical Informatics Association 1994, p. 121.

Banerjee, Abhijit V and Esther Duflo, "(Dis)organization and Success in an Economics MOOC," AEA Papers and Proceedings, 2014.

Baumeister, Roy F and Kathleen D Vohs, "Willpower, Choice, and Self-Control," 2003.

_, Ellen Bratslavsky, Mark Muraven, and Dianne M Tice, "Ego Depletion: Is the Active Self a Limited Resource?," Journal of personality and social psychology, May 1998, $74(5), 1252-65$.

Breslow, Lori B, David E Pritchard, Jennifer DeBoer, Glenda S Stump, Andrew D Ho, and Daniel T Seaton, "Studying Learning in the Worldwide Classroom: Research into edX's First MOOC," Research 83 Practice in Assessment, 2013, 8, 13-25.

Bryan, Gharad, Dean Karlan, and Scott Nelson, "Commitment Devices," Annual Review of Economics, September 2010, 2 (1), 671-698.

Cadena, Ximena and Antoinette Schoar, "Remembering to Pay? Reminders vs. Financial Incentives for Loan Payments," 2011.

Calzolari, Giacomo and Mattia Nardotto, "Nudging with Information: A Randomized Field Experiment," 2012.

Castleman, Benjamin L and Lindsay C Page, "A Trickle or a Torrent? Understanding the Extent of Summer Melt Among CollegeIntending High School Graduates," Social Science Quarterly, 2014, 95 (1), 202-220. 
Richard W. Patterson

Doherty, William, "An Analysis of Multiple Factors Affecting Retention in Web-Based Community College Courses," The Internet and Higher Education, October 2006, 9 (4), $245-255$.

Ericson, Keith M Marzilli, "Forgetting We Forget: Overconfidence and Memory," Journal of the European Economic Association, 2011, 9 (1), 43-60.

_ , "On the Interaction of Memory and Procrastination: Implications for Reminders," 2014.

Fudenberg, Drew and David K Levine, "A Dual-Self Model of Impulse Control," The American Economic Review, December 2006, 96 (5), 1449-1476.

_ and _ ,"Timing and Self-Control," Econometrica, January 2012, 80 (1), 1-42.

Ginder, Scott and Christina Stearns, "Enrollment in Distance Education Courses, by State: Fall 2012," 2014.

Giné, Xavier, Dean Karlan, and Jonathan Zinman, "Put Your Money Where Your Butt Is: A Commitment Contract for Smoking Cessation," American Economic Journal: Applied Economics, 2010, pp. 213-235.

Karlan, Dean, Margaret McConnell, Sendhil Mullainathan, and Jonathan Zinman, "Getting to the Top of Mind: How Reminders Increase Saving," 2010.

Kast, Felipe, Stephan Meier, and Dina Pomeranz, "Under-Savers Anonymous: Evidence on Self-Help Groups and Peer Pressure as a Savings Commitment Device," 2012.

Kaur, Supreet, Michael Kremer, and Sendhil Mullainathan, "Self-Control at Work," 2011.

Krishna, Santosh, Suzanne Austin Boren, and E Andrew Balas, "Healthcare Via Cell Phones: A Systematic Review," Telemedicine and e-Health, 2009, 15 (3), 231-240.

Laibson, David, "Golden Eggs and Hyperbolic Discounting," The Quarterly Journal of Economics, May 1997, 112 (2), 443-478.

Levitt, Steven D, John A List, Susanne Neckermann, and Sally Sadoff, "The Behavioralist Goes to School: Leveraging Behavioral Economics to Improve Educational Performance," 2012.

Madrian, Brigitte C and Dennis F Shea, "The Power of Suggestion: Inertia in $401(\mathrm{k})$ Participation and Savings Behavior," Quarterly Journal of Economics, 2001, pp. 11491187.

McDaniel, Mark A and Gilles O Einstein, Prospective Memory: An Overview and Synthesis of an Emerging Field, Sage Publications, 2007. 
Richard W. Patterson

Mullainathan, Sendhil, "A Memory-Based Model of Bounded Rationality," The Quarterly Journal of Economics, August 2002, 117 (3), 735-774.

O'Donoghue, Ted and Matthew Rabin, "Doing It Now or Later," The American Economic Review, February 1999, 151 (3712), 867-8.

Ozdenoren, Emre, Stephen W Salant, and Dan Silverman, "Willpower and the Optimal Control of Visceral Urges," Journal of the European Economic Association, April $2012,10(2), 342-368$.

Perna, Laura, Alan Ruby, Robert Boruch, Nicole Wang, Janie Scull, Chad Evans, and Seher Ahmad, "The Life Cycle of a Million MOOC Users," 2013.

Taubinsky, Dmitry, "From Intentions to Actions: A Model and Experimental Evidence of Inattentive Choice," 2014.

Thaler, Richard H and Shlomo Benartzi, "Save More Tomorrow: Using Behavioral Economics to Increase Employee Saving," Journal of Political Economy, 2004, 112 (S1), S164-S187.

Waldrop, M Mitchell, "Massive Open Online Courses, aka MOOCs, Transform Higher Education and Science," Nature Magazine, 2014, pp. 1-5.

Wilkowski, Julia, Amit Deutsch, and Daniel M Russell, "Student Skill and Goal Achievement in the Mapping with Google MOOC," in "Proceedings of the first ACM conference on Learning at scale conference" ACM 2014, pp. 3-10.

Winters, Fielding I., Jeffrey a. Greene, and Claudine M. Costich, "Self-Regulation of Learning within Computer-based Learning Environments: A Critical Analysis," Educational Psychology Review, July 2008, 20 (4), 429-444.

Xu, Di and Shanna Jaggars, "Online and Hybrid Course Enrollment and Performance in Washington State Community and Technical Colleges," 2011.

Zizzo, Daniel John, "Experimenter Demand Effects in Economic Experiments," Experimental Economics, 2010, 13 (1), 75-98.

Zogg, Jennifer B, Steven Paul Woods, John A Sauceda, John S Wiebe, and Jane M Simoni, "The role of prospective memory in medication adherence: a review of an emerging literature," Journal of Behavioral Medicine, 2012, 35 (1), 47-62. 


\section{Tables and Figures}

Table 6: Treatment Summary Statistics

\begin{tabular}{|c|c|c|c|c|c|}
\hline & Control & Commitment & Reminder & Focus & Total \\
\hline \multicolumn{6}{|l|}{ Software Summary } \\
\hline Days logged on software & $\begin{array}{c}38.32 \\
(24.08)\end{array}$ & $\begin{array}{c}33.75 \\
(24.84)\end{array}$ & $\begin{array}{c}36.75 \\
(24.01)\end{array}$ & $\begin{array}{c}37.45 \\
(25.13)\end{array}$ & $\begin{array}{c}36.60 \\
(24.52)\end{array}$ \\
\hline Avg hours productive & $\begin{array}{c}1.74 \\
(1.49)\end{array}$ & $\begin{array}{c}1.71 \\
(1.42)\end{array}$ & $\begin{array}{c}1.62 \\
(1.34)\end{array}$ & $\begin{array}{c}1.88 \\
(1.47)\end{array}$ & $\begin{array}{c}1.74 \\
(1.43)\end{array}$ \\
\hline Avg hours unproductive & $\begin{array}{c}0.94 \\
(0.97)\end{array}$ & $\begin{array}{c}0.90 \\
(0.93)\end{array}$ & $\begin{array}{l}1.00 \\
(1.33)\end{array}$ & $\begin{array}{c}0.90 \\
(1.03)\end{array}$ & $\begin{array}{c}0.93 \\
(1.08)\end{array}$ \\
\hline Avg hours on course & $\begin{array}{c}0.16 \\
(0.24)\end{array}$ & $\begin{array}{c}0.19 \\
(0.24)\end{array}$ & $\begin{array}{c}0.15 \\
(0.20)\end{array}$ & $\begin{array}{c}0.15 \\
(0.21)\end{array}$ & $\begin{array}{c}0.16 \\
(0.22)\end{array}$ \\
\hline Times visited RescueTime & $\begin{array}{c}18.59 \\
(17.25)\end{array}$ & $\begin{array}{c}15.53 \\
(15.42)\end{array}$ & $\begin{array}{c}17.07 \\
(16.99)\end{array}$ & $\begin{array}{c}15.35 \\
(15.68)\end{array}$ & $\begin{array}{c}16.67 \\
(16.39)\end{array}$ \\
\hline \multicolumn{6}{|l|}{ Commitment Device } \\
\hline Commitment emails sent & - & $\begin{array}{l}67.18 \\
(8.32)\end{array}$ & - & - & - \\
\hline Commitment (hours) & $\begin{array}{l}- \\
- \\
-\end{array}$ & $\begin{array}{c}2.69 \\
(2.71)\end{array}$ & $\begin{array}{l}- \\
- \\
-\end{array}$ & $\begin{array}{l}- \\
- \\
-\end{array}$ & $\begin{array}{l}- \\
- \\
-\end{array}$ \\
\hline Times commitment exceeded & - & $\begin{array}{c}4.06 \\
(8.25)\end{array}$ & - & - & - \\
\hline Times commitment changed & - & $\begin{array}{c}0.92 \\
(1.79)\end{array}$ & - & $\begin{array}{l}- \\
- \\
-\end{array}$ & $\begin{array}{l}- \\
- \\
-\end{array}$ \\
\hline Avg change (hours) & $\begin{array}{l}- \\
- \\
-\end{array}$ & $\begin{array}{c}2.61 \\
(2.86)\end{array}$ & - & $\begin{array}{l}- \\
- \\
-\end{array}$ & $\begin{array}{l}- \\
- \\
-\end{array}$ \\
\hline Reminders & & & & & \\
\hline Reminders sent & $\begin{array}{l}- \\
- \\
-\end{array}$ & - & $\begin{array}{c}48.19 \\
(77.64)\end{array}$ & $\begin{array}{l}- \\
- \\
-\end{array}$ & $\begin{array}{l}- \\
- \\
-\end{array}$ \\
\hline Focus Study & & & & & \\
\hline Times prompted & - & - & - & $\begin{array}{c}9.22 \\
(10.33)\end{array}$ & - \\
\hline Times initiated & - & $\begin{array}{l}- \\
- \\
-\end{array}$ & - & $\begin{array}{c}1.93 \\
(3.55)\end{array}$ & $\begin{array}{l}- \\
- \\
-\end{array}$ \\
\hline Average duration & $\begin{array}{l}- \\
- \\
-\end{array}$ & $\begin{array}{l}- \\
- \\
-\end{array}$ & - & $\begin{array}{c}38.24 \\
(15.83)\end{array}$ & $\begin{array}{l}- \\
- \\
-\end{array}$ \\
\hline Observations & 170 & 160 & 166 & 161 & 657 \\
\hline
\end{tabular}

Notes: Standard deviations in parentheses. Summaries for hours of productive, unproductive, and course time exclude days for which the software was inactive. 
Richard W. Patterson

Table 7: Impact of Treatments on Course Outcomes

\begin{tabular}{lcccc}
\hline \hline & $\begin{array}{c}\text { Course Effort } \\
\text { (Hours) }\end{array}$ & $\begin{array}{c}\text { Homework } \\
\text { Submitted }\end{array}$ & $\begin{array}{c}\text { Course Grade } \\
\text { (Z-score) }\end{array}$ & $\begin{array}{c}\text { Course } \\
\text { Completion }\end{array}$ \\
\hline Commitment device & $5.491^{*}$ & $0.909^{* *}$ & $0.291^{* * *}$ & $0.107^{* *}$ \\
Reminder & $(3.085)$ & $(0.403)$ & $(0.148)$ & $(0.0497)$ \\
& -3.339 & 0.267 & 0.0109 & 0.0108 \\
Focused study & $(2.597)$ & $(0.415)$ & $(0.150)$ & $(0.0503)$ \\
& 0.848 & 0.577 & 0.0966 & 0.0135 \\
Dep var mean & $(2.826)$ & $(0.412)$ & $(0.149)$ & $(0.0498)$ \\
Demographics & 22.38 & 3.730 & 0.711 & 0.289 \\
Course variables & $\mathrm{y}$ & $\mathrm{y}$ & $\mathrm{y}$ & $\mathrm{y}$ \\
Self-control variables & $\mathrm{y}$ & $\mathrm{y}$ & $\mathrm{y}$ & $\mathrm{y}$ \\
Observations & 657 & 657 & 657 & $\mathrm{y}$ \\
R-squared & 0.177 & 0.158 & 0.136 & 6.152 \\
\hline
\end{tabular}

${ }^{* * *} \mathrm{p}<0.01,{ }^{*} \mathrm{p}<0.05,{ }^{*} \mathrm{p}<0.1$. Robust standard errors in parentheses. Demographic variables include gender, age, age ${ }^{2}$, education, income, continent, and indicators for missing age and income variables. Course variables include course goals: finish for certificate, finish at own pace, complete some assignments, or watch some videos, reasons taking the course: general interest, relevant to school/work/research, career change, fun, try online course, improve English, type of computer: personal laptop, personal desktop, work computer, previous online courses started, previous online courses finished, previous statistics courses taken, interest level in course, expected course hours, and importance of finishing course. Self-control variables include distracting time goal, desired change in distracting time, self reported difficulty breaking habits, distractibility, ability to resist temptation, level of self-discipline, and take actions that are regretted in long run. 
Richard W. Patterson

Table 8: Heterogeneous Treatment Effects, Goals

\begin{tabular}{lcccc}
\hline \hline & $\begin{array}{c}\text { Course Effort } \\
\text { (Hours) }\end{array}$ & $\begin{array}{c}\text { Homework } \\
\text { Submitted }\end{array}$ & $\begin{array}{c}\text { Course Grade } \\
\text { (Z-score) }\end{array}$ & $\begin{array}{c}\text { Course } \\
\text { Completion }\end{array}$ \\
\hline Commitment*Importance & $9.898^{*}$ & 1.068 & 0.457 & 0.136 \\
Reminder*Importance & $(5.813)$ & $(0.843)$ & $(0.306)$ & $(0.103)$ \\
Focus*Importance & -1.659 & 0.804 & 0.311 & 0.115 \\
Commitment device & $(5.010)$ & $(0.847)$ & $(0.300)$ & $(0.0995)$ \\
& 0.142 & 0.0808 & 0.194 & 0.0589 \\
Reminder & $(5.600)$ & $(0.840)$ & $(0.297)$ & $(0.0995)$ \\
& -2.172 & 0.0793 & -0.0442 & 0.00763 \\
Focused study & $(3.820)$ & $(0.666)$ & $(0.234)$ & $(0.0788)$ \\
& -3.472 & -0.263 & -0.194 & -0.0639 \\
Important to complete & $(3.311)$ & $(0.634)$ & $(0.221)$ & $(0.0703)$ \\
& 0.306 & 0.505 & -0.0369 & -0.0294 \\
Dep var mean & $(3.721)$ & $(0.637)$ & $(0.220)$ & $(0.0729)$ \\
Demographic variables & $9.277^{* *}$ & $0.994^{*}$ & 0.233 & 0.0689 \\
Course variables & $(4.037)$ & $(0.594)$ & $(0.217)$ & $(0.0704)$ \\
Self-control variables & 22.38 & 3.730 & 0.289 & 0.711 \\
Observations & $\mathrm{y}$ & $\mathrm{y}$ & $\mathrm{y}$ & $\mathrm{y}$ \\
R-squared & $\mathrm{y}$ & $\mathrm{y}$ & $\mathrm{y}$ & $\mathrm{y}$ \\
\hline & 657 & $\mathrm{y}$ & $\mathrm{y}$ & $\mathrm{y}$ \\
\hline p & 0.163 & 0.132 & 0.129 & 657 \\
& & 657 & & 0.116 \\
\hline
\end{tabular}

*** $\mathrm{p}<0.01, * * \mathrm{p}<0.05, * \mathrm{p}<0.1$. Robust standard errors in parentheses. "Important to complete" variable is an indicator for whether students indicate that it is either very or extremely important to finish assignments and tests on-time for credit. Demographic variables include gender, age, age ${ }^{2}$, education, income, continent, and indicators for missing age and income variables. Course variables include type of computer: personal laptop, personal desktop, work computer, previous online courses started, previous online courses finished, and previous statistics courses taken. Self-control variables include distracting time goal, desired change in distracting time, self reported difficulty breaking habits, distractibility, ability to resist temptation, level of self-discipline, and take actions that are regretted in long run. 
Richard W. Patterson

Table 9: Heterogeneous Treatment Effects, Predicted Outcomes

\begin{tabular}{lccccc}
\hline \hline & \multicolumn{5}{c}{ Quintile of Predicted Outcome } \\
& $(1)$ & $(2)$ & $(3)$ & $(4)$ & $(5)$ \\
\hline Course Effort (Hours) & & & & & \\
Commitment device & -2.031 & 0.272 & 4.958 & 6.512 & 9.362 \\
& $(3.835)$ & $(3.159)$ & $(3.627)$ & $(4.633)$ & $(6.889)$ \\
Reminder & -4.223 & $-5.178^{* *}$ & $-6.265^{* *}$ & $-8.054^{* * *}$ & -2.609 \\
& $(3.625)$ & $(2.482)$ & $(2.598)$ & $(2.994)$ & $(3.797)$ \\
Focused study & -0.618 & -1.701 & -1.736 & -2.131 & -0.003 \\
& $(3.809)$ & $(2.956)$ & $(3.464)$ & $(4.262)$ & $(6.727)$ \\
\hline Homework Submitted & & & & & \\
Commitment device & -0.161 & 0.034 & 0.723 & $1.126^{*}$ & $1.841^{* * *}$ \\
& $(0.643)$ & $(0.476)$ & $(0.571)$ & $(0.630)$ & $(0.640)$ \\
Reminder & -0.005 & -0.037 & 0.060 & 0.308 & 0.784 \\
& $(0.625)$ & $(0.452)$ & $(0.559)$ & $(0.600)$ & $(0.649)$ \\
Focused study & 0.089 & -0.075 & 0.322 & 0.848 & $1.345^{* *}$ \\
& $(0.590)$ & $(0.457)$ & $(0.576)$ & $(0.621)$ & $(0.678)$ \\
\hline Course Grade (Z-score) & & & & & \\
Commitment device & -0.140 & 0.081 & 0.259 & 0.354 & $0.570^{* *}$ \\
& $(0.220)$ & $(0.163)$ & $(0.194)$ & $(0.254)$ & $(0.269)$ \\
Reminder & -0.068 & -0.132 & -0.021 & -0.031 & 0.102 \\
& $(0.215)$ & $(0.153)$ & $(0.185)$ & $(0.233)$ & $(0.256)$ \\
Focused study & -0.135 & -0.104 & 0.014 & 0.178 & 0.303 \\
& $(0.208)$ & $(0.154)$ & $(0.192)$ & $(0.249)$ & $(0.272)$ \\
\hline
\end{tabular}

**** $p<0.01$, ** $p<0.05$, * $p<0.1$. Bootstrap standard errors in parentheses. Split-sample endogenous stratification estimates reported (Abadie et al., 2013). Estimates are generated with 200 sample splits and 500 bootstrap repetitions. Variables used to construct predicted values include demographic, course, and self control variables. Demographic variables include gender, age, age ${ }^{2}$, education, income, continent, and indicators for missing age and income variables. Course variables include course goals: finish for certificate, finish at own pace, complete some assignments, or watch some videos, reasons taking the course: general interest, relevant to school/work/research, career change, fun, try online course, improve English, type of computer: personal laptop, personal desktop, work computer, previous online courses started, previous online courses finished, previous statistics courses taken, interest level in course, expected course hours, and importance of finishing course. Self-control variables include distracting time goal, desired change in distracting time, self reported difficulty breaking habits, distractibility, ability to resist temptation, level of self-discipline, and take actions that are regretted in long run. 
Table 10: Post Study Survey Responses

\begin{tabular}{|c|c|c|c|c|}
\hline & Control & Commitment & Reminder & Focus \\
\hline Completed post survey & 0.465 & $0.650^{* *}$ & 0.482 & 0.503 \\
\hline Software increased thinking about course & 0.413 & 0.505 & 0.487 & 0.438 \\
\hline Software reduced distracting time & 0.413 & 0.485 & 0.526 & 0.354 \\
\hline Software increased time spent on course & 0.320 & 0.402 & 0.308 & 0.237 \\
\hline Software made unproductive time less enjoyable & 0.280 & $0.510^{* * * *}$ & $0.449^{* *}$ & 0.291 \\
\hline Software improved understanding of time use & 0.627 & 0.656 & 0.756 & 0.544 \\
\hline Used software to set course goals & 0.189 & 0.271 & 0.205 & 0.175 \\
\hline Used software to set general goals & 0.347 & 0.375 & 0.397 & $0.215^{*}$ \\
\hline Software was useful & 0.467 & 0.542 & 0.564 & 0.423 \\
\hline Observations & 170 & 160 & 166 & 161 \\
\hline
\end{tabular}


Figure 5: Effort (in Hours), by Week
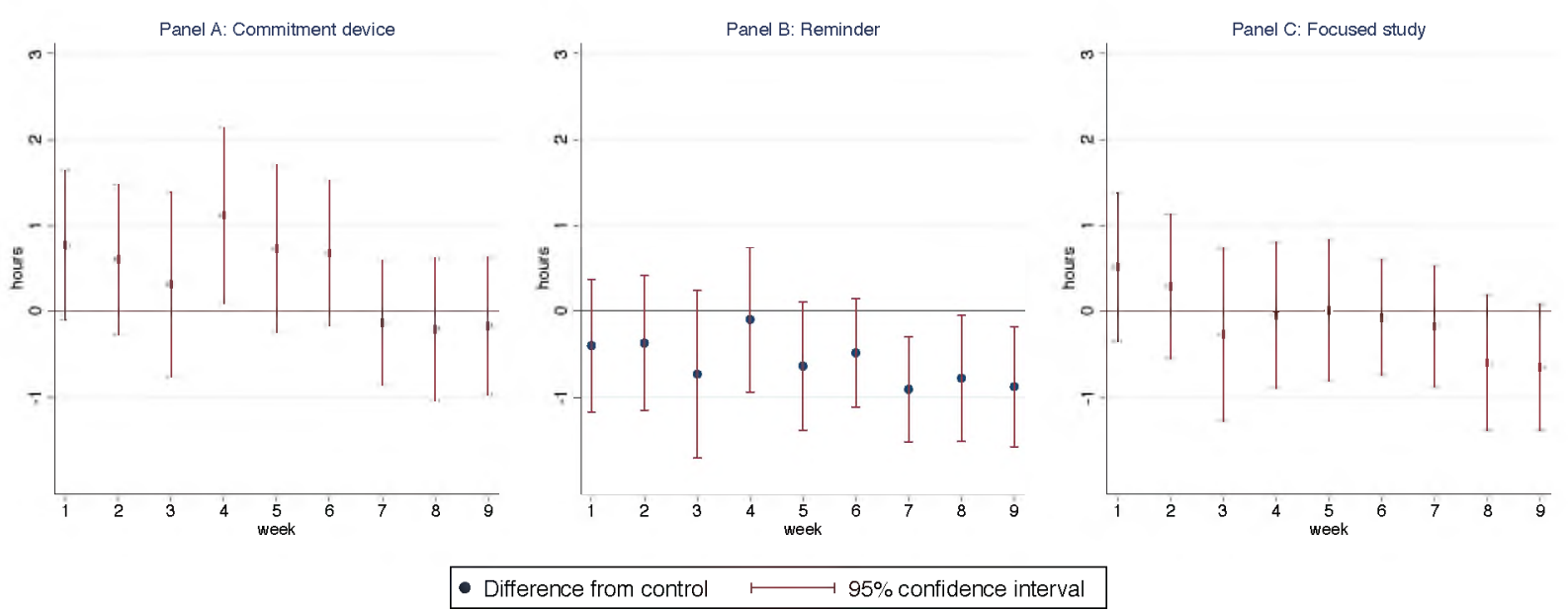

Panels $\mathrm{A}, \mathrm{B}$, and $\mathrm{C}$ show estimated differences in weekly hours spent on course between treatment and control $\left(\gamma_{j}+\lambda_{j t}\right.$ in equation 2) for commitment device, reminder, and focusing treatments, respectively. Bounds represent $95 \%$ confidence intervals. Estimates are generated from an OLS panel estimation with controls for demographic, course, and self-control variables. Standard errors are clustered at the individual level. 
Richard W. Patterson

Figure 6: Homework Assignments Submitted, by Week
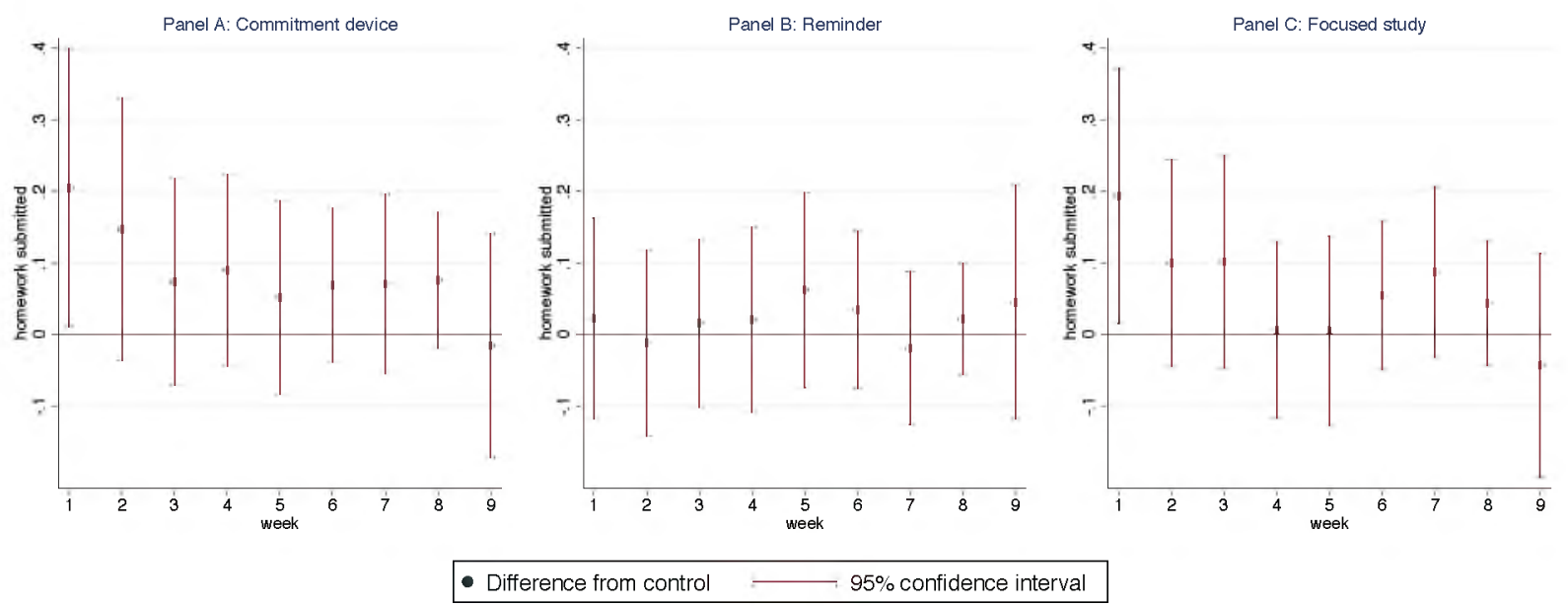

Panels $\mathrm{A}, \mathrm{B}$, and $\mathrm{C}$ show estimated differences in weekly homework submissions between treatment and control $\left(\gamma_{j}+\lambda_{j t}\right.$ in equation 2) for commitment device, reminder, and focusing treatments, respectively. Bounds represent $95 \%$ confidence intervals. Estimates are generated from an OLS panel estimation with controls for demographic, course, and self-control variables. Standard errors are clustered at the individual level. 
Richard W. Patterson

Figure 7: On-time Homework Submissions, by Week
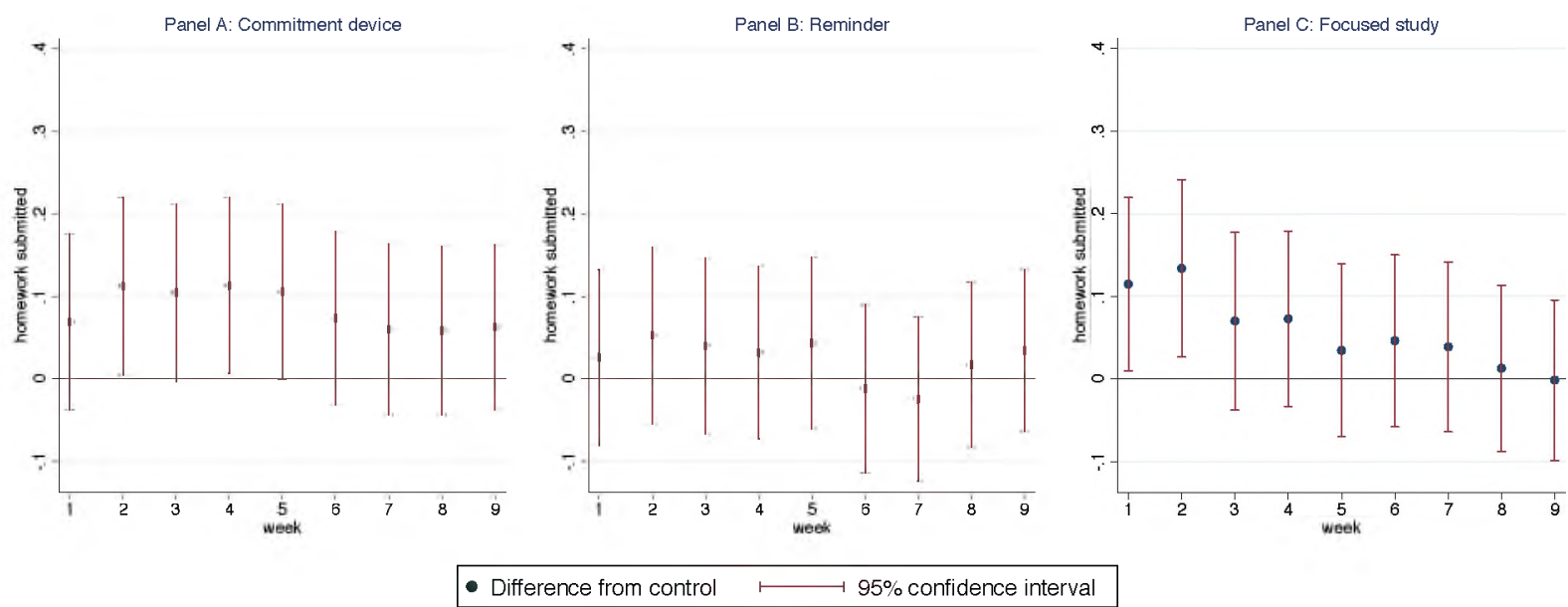

Panels A, B, and C show estimated differences in whether students submitted weekly homework assignments on-time between treatment and control $\left(\gamma_{j}+\lambda_{j t}\right.$ in equation 2) for commitment device, reminder, and focusing treatments, respectively. Bounds represent $95 \%$ confidence intervals. Estimates are generated from an OLS panel estimation with controls for demographic, course, and self-control variables. Standard errors are clustered at the individual level. 
Figure 8: Software Installed, by Week
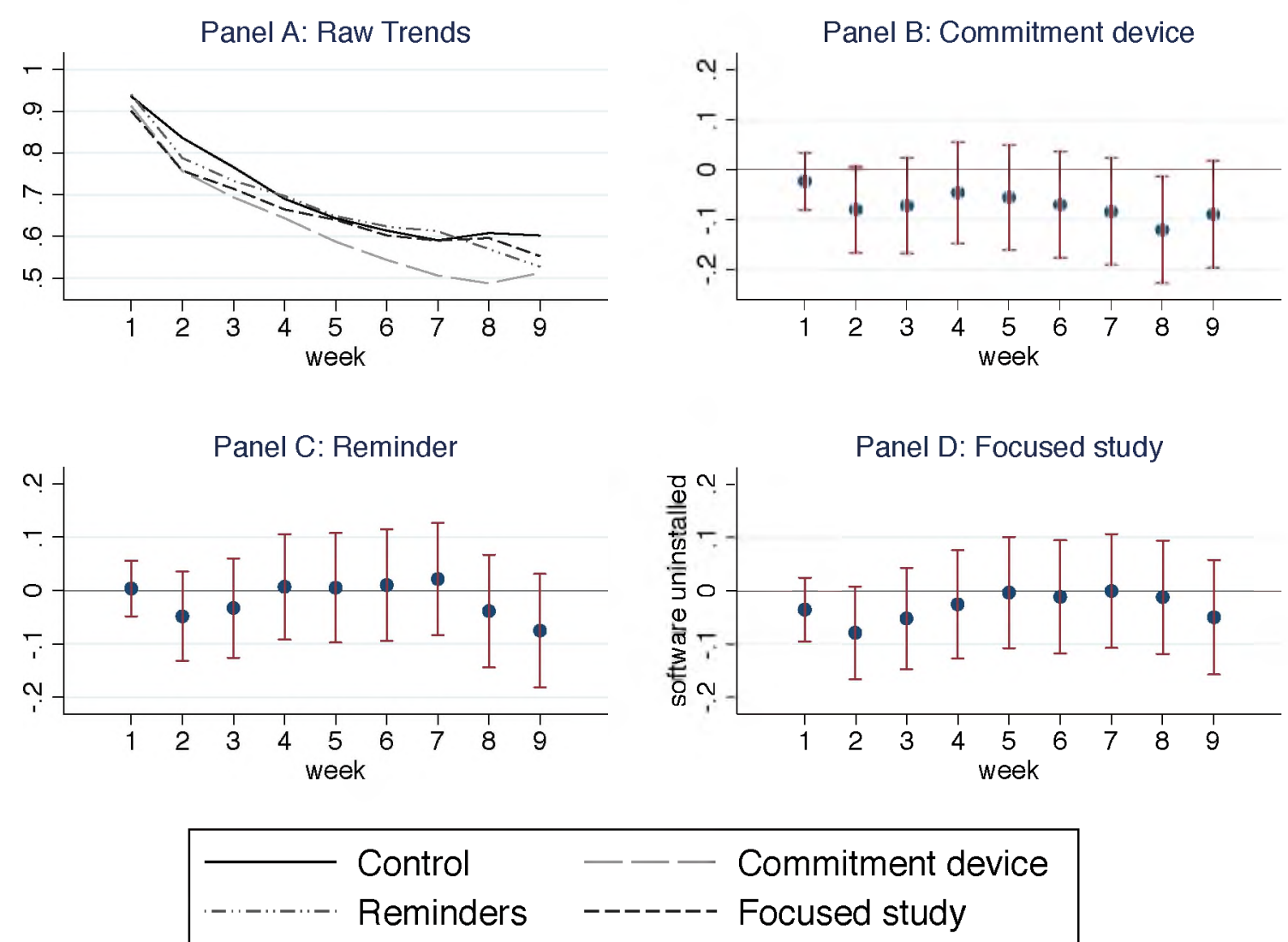

Panel A presents the raw trends for whether software was installed by treatment and week. Panels B, C, and D show coefficient estimates and 95\% confidence intervals for commitment device, reminder, and focusing treatment effects, respectively. Estimated coefficients and confidence intervals are generated from an OLS panel estimation which included treatment, week, and treatment*week indicators along with demographic, course, and self-control variables. Standard errors are clustered at the individual level. 
Richard W. Patterson 


\section{A Appendix}

Richard W. Patterson

Table A.1: Summary Statistics

\begin{tabular}{|c|c|c|c|c|c|}
\hline & Control & Commitment & Reminder & Focus & $\begin{array}{c}\text { F-stat } \\
\text { P-value }\end{array}$ \\
\hline \multicolumn{6}{|l|}{ Panel A- Demographic Characteristics } \\
\hline Age & 32.094 & 30.169 & 30.367 & 30.161 & 0.295 \\
\hline Female & 0.465 & 0.438 & 0.373 & 0.416 & 0.381 \\
\hline High school & 0.065 & 0.094 & 0.078 & 0.075 & 0.811 \\
\hline Bachelors degree & 0.182 & 0.219 & 0.229 & 0.205 & 0.736 \\
\hline Masters degree & 0.394 & 0.338 & 0.271 & 0.317 & 0.115 \\
\hline $\mathrm{PhD} / \mathrm{MD}$ & 0.318 & 0.287 & 0.337 & 0.317 & 0.810 \\
\hline United States & 0.282 & 0.275 & 0.235 & 0.311 & 0.483 \\
\hline Africa & 0.165 & 0.131 & 0.139 & 0.075 & 0.049 \\
\hline Asia & 0.176 & 0.188 & 0.217 & 0.205 & 0.797 \\
\hline Australia & 0.035 & 0.013 & 0.036 & 0.037 & 0.285 \\
\hline Europe & 0.235 & 0.244 & 0.247 & 0.230 & 0.983 \\
\hline North America & 0.047 & 0.075 & 0.066 & 0.050 & 0.677 \\
\hline South America & 0.059 & 0.075 & 0.060 & 0.093 & 0.631 \\
\hline Income: $\$ 0-\$ 19,999$ & 0.259 & 0.294 & 0.277 & 0.236 & 0.344 \\
\hline Income: $\$ 20,000-\$ 59,999$ & 0.253 & 0.225 & 0.229 & 0.335 & 0.145 \\
\hline Income: $\$ 60,000-\$ 99,999$ & 0.182 & 0.100 & 0.108 & 0.087 & 0.080 \\
\hline Income: $\$ 100,000+$ & 0.112 & 0.131 & 0.114 & 0.130 & 0.870 \\
\hline \multicolumn{6}{|c|}{ Panel B- Course Experience Characteristics } \\
\hline Goal: complete course ontime for certificate & 0.659 & 0.637 & 0.669 & 0.714 & 0.502 \\
\hline Goal: complete course at own pace & 0.241 & 0.225 & 0.235 & 0.143 & 0.060 \\
\hline Goal: other & 0.094 & 0.131 & 0.084 & 0.130 & 0.390 \\
\hline Importance of finishing material ${ }^{\dagger}$ & 3.724 & 3.694 & 3.578 & 3.696 & 0.433 \\
\hline Expected hours on course & 54.953 & 52.875 & 49.663 & 55.761 & 0.404 \\
\hline Reason: relevant to job, school, or research & 0.959 & 0.919 & 0.904 & 0.913 & 0.007 \\
\hline Reason: general interest & 0.941 & 0.938 & 0.952 & 0.925 & 0.556 \\
\hline Reason: personal growth & 0.906 & 0.938 & 0.940 & 0.925 & 0.994 \\
\hline Reason: career change & 0.288 & 0.306 & 0.349 & 0.335 & 0.578 \\
\hline Reason: for fun & 0.612 & 0.613 & 0.608 & 0.615 & 0.968 \\
\hline Reason: try online course & 0.447 & 0.450 & 0.530 & 0.460 & 0.235 \\
\hline Previous statistics courses taken & 1.353 & 1.387 & 1.157 & 1.304 & 0.468 \\
\hline Previous online courses started & 4.300 & 6.606 & 4.886 & 4.981 & 0.443 \\
\hline Previous online courses finished & 1.859 & 2.731 & 1.867 & 2.093 & 0.649 \\
\hline Software installed: personal laptop & 0.712 & 0.756 & 0.663 & 0.708 & 0.320 \\
\hline Software installed: personal desktop & 0.165 & 0.113 & 0.187 & 0.118 & 0.164 \\
\hline Software installed: work computer & 0.112 & 0.113 & 0.133 & 0.168 & 0.446 \\
\hline \multicolumn{6}{|l|}{ Panel C- Self Control Characteristics } \\
\hline Goal: distracting time & 1.132 & 1.269 & 1.173 & 1.273 & 0.561 \\
\hline Goal: change in distracting time & -1.129 & -1.015 & -1.208 & -1.065 & 0.646 \\
\hline Hard to break habits. & 2.871 & 2.950 & 3.096 & 3.087 & 0.070 \\
\hline Easily distracted $\mathrm{d}^{\ddagger}$ & 3.029 & 3.006 & 3.187 & 3.211 & 0.216 \\
\hline Able to resist tempation & 3.147 & 3.081 & 2.976 & 2.957 & 0.332 \\
\hline Strong self discipline $e^{\frac{t}{2}}$ & 3.347 & 3.325 & 3.247 & 3.422 & 0.706 \\
\hline Pleasure/fun gets in way of productivity & 2.753 & 2.825 & 2.940 & 2.975 & 0.087 \\
\hline Do things that regret later ${ }^{\ddagger}$ & 2.547 & 2.556 & 2.699 & 2.640 & 0.397 \\
\hline Observations & 170 & 160 & 166 & 161 & Total $=657$ \\
\hline
\end{tabular}

Notes: $†$ 1-Not at all important, 5-Extremely important. $\ddagger$ 1-Not like me at all, 5-Very much like me. 
Table A.2: Summary Statistics: Sample Comparison

\begin{tabular}{|c|c|c|c|}
\hline & In Sample & $\begin{array}{l}\text { Out of } \\
\text { Sample }\end{array}$ & $\begin{array}{l}\text { F-Stat } \\
\text { P-value }\end{array}$ \\
\hline Age & $\begin{array}{c}30.782 \\
(12.070)\end{array}$ & $\begin{array}{c}30.681 \\
(14.490)\end{array}$ & 0.857 \\
\hline Female & $\begin{array}{c}0.422 \\
(0.494)\end{array}$ & $\begin{array}{c}0.378 \\
(0.485)\end{array}$ & 0.035 \\
\hline High school & $\begin{array}{c}0.077 \\
(0.267)\end{array}$ & $\begin{array}{c}0.071 \\
(0.257)\end{array}$ & 0.625 \\
\hline Bachelor's degree & $\begin{array}{c}0.208 \\
(0.406)\end{array}$ & $\begin{array}{c}0.240 \\
(0.427)\end{array}$ & 0.071 \\
\hline Master's degree & $\begin{array}{c}0.332 \\
(0.471)\end{array}$ & $\begin{array}{c}0.365 \\
(0.482)\end{array}$ & 0.110 \\
\hline Ph.D./M.D. & $\begin{array}{c}0.317 \\
(0.466)\end{array}$ & $\begin{array}{c}0.186 \\
(0.389)\end{array}$ & 0.000 \\
\hline Effort (hours) & $\begin{array}{c}22.378 \\
(25.241)\end{array}$ & $\begin{array}{c}15.755 \\
(23.326)\end{array}$ & 0.000 \\
\hline Homework assignments submitted & $\begin{array}{c}3.799 \\
(3.730)\end{array}$ & $\begin{array}{c}2.674 \\
(3.528)\end{array}$ & 0.000 \\
\hline Aggregate course score (out of 100) & $\begin{array}{c}31.394 \\
(36.693)\end{array}$ & $\begin{array}{c}22.694 \\
(34.431)\end{array}$ & 0.000 \\
\hline Course completion & $\begin{array}{c}0.289 \\
(0.454)\end{array}$ & $\begin{array}{c}0.213 \\
(0.409)\end{array}$ & 0.000 \\
\hline Observations & 657 & 2903 & \\
\hline
\end{tabular}

Notes: Standard deviations (SD) in parentheses. Out of sample students include all students pre-enrolling in MOOC. Statistics come from pre-course survey administered by Stanford. 
Richard W. Patterson

Table A.3: Impact of Treatments on Course Outcomes

\begin{tabular}{|c|c|c|c|c|c|c|c|c|}
\hline & \multicolumn{4}{|c|}{ Primary Sample } & \multicolumn{4}{|c|}{ Primary Sample + Late Enrollees } \\
\hline & (1) & $(2)$ & (3) & (4) & (5) & (6) & $(7)$ & (8) \\
\hline \multicolumn{9}{|l|}{ Course Effort (Hours) } \\
\hline Commitment device & $\begin{array}{c}3.712 \\
(3.137)\end{array}$ & $\begin{array}{c}4.619 \\
(3.159)\end{array}$ & $\begin{array}{l}5.486^{*} \\
(3.067)\end{array}$ & $\begin{array}{c}5.491^{*} \\
(3.085)\end{array}$ & $\begin{array}{c}3.282 \\
(2.696)\end{array}$ & $\begin{array}{c}3.560 \\
(2.720)\end{array}$ & $\begin{array}{c}3.721 \\
(2.600)\end{array}$ & $\begin{array}{c}3.940 \\
(2.618)\end{array}$ \\
\hline Reminder & $\begin{array}{c}-5.298^{* *} * \\
(2.614)\end{array}$ & $\begin{array}{l}-3.987 \\
(2.605)\end{array}$ & $\begin{array}{l}-2.745 \\
(2.598)\end{array}$ & $\begin{array}{l}-3.339 \\
(2.597)\end{array}$ & $\begin{array}{c}-5.596^{* * *} \\
(2.232)\end{array}$ & $\begin{array}{c}-4.653^{* *} \\
(2.251)\end{array}$ & $\begin{array}{c}-3.710^{*} \\
(2.207)\end{array}$ & $\begin{array}{c}-4.207^{*} \\
(2.202)\end{array}$ \\
\hline Focused study & $\begin{array}{c}-0.986 \\
(2.778)\end{array}$ & $\begin{array}{c}0.161 \\
(2.760)\end{array}$ & $\begin{array}{c}0.344 \\
(2.723)\end{array}$ & $\begin{array}{c}0.848 \\
(2.826)\end{array}$ & $\begin{array}{c}-2.862 \\
(2.375)\end{array}$ & $\begin{array}{l}-1.781 \\
(2.311)\end{array}$ & $\begin{array}{l}-1.898 \\
(2.261)\end{array}$ & $\begin{array}{l}-1.348 \\
(2.303)\end{array}$ \\
\hline \multicolumn{9}{|l|}{ Homework Submitted } \\
\hline Commitment device & $\begin{array}{l}0.761^{*} \\
(0.416)\end{array}$ & $\begin{array}{c}0.865^{* *} \\
(0.415)\end{array}$ & $\begin{array}{c}0.928^{* * *} \\
(0.401)\end{array}$ & $\begin{array}{c}0.909^{* *} \\
(0.403)\end{array}$ & $\begin{array}{c}0.479 \\
(0.361)\end{array}$ & $\begin{array}{c}0.507 \\
(0.361)\end{array}$ & $\begin{array}{c}0.517 \\
(0.347)\end{array}$ & $\begin{array}{c}0.529 \\
(0.345)\end{array}$ \\
\hline Reminder & $\begin{array}{c}0.210 \\
(0.408)\end{array}$ & $\begin{array}{c}0.224 \\
(0.414)\end{array}$ & $\begin{array}{c}0.321 \\
(0.414)\end{array}$ & $\begin{array}{c}0.267 \\
(0.415)\end{array}$ & $\begin{array}{c}-0.273 \\
(0.350)\end{array}$ & $\begin{array}{c}-0.279 \\
(0.357)\end{array}$ & $\begin{array}{c}-0.155 \\
(0.345)\end{array}$ & $\begin{array}{c}-0.204 \\
(0.345)\end{array}$ \\
\hline Focused study & $\begin{array}{c}0.524 \\
(0.405)\end{array}$ & $\begin{array}{c}0.583 \\
(0.412)\end{array}$ & $\begin{array}{c}0.554 \\
(0.406)\end{array}$ & $\begin{array}{c}0.577 \\
(0.412)\end{array}$ & $\begin{array}{l}0.0433 \\
(0.347)\end{array}$ & $\begin{array}{c}0.130 \\
(0.352)\end{array}$ & $\begin{array}{l}0.0850 \\
(0.342)\end{array}$ & $\begin{array}{c}0.128 \\
(0.343)\end{array}$ \\
\hline \multicolumn{9}{|l|}{ Course Grade (Z-score) } \\
\hline Commitment device & $\begin{array}{c}0.219 \\
(0.152)\end{array}$ & $\begin{array}{c}0.273^{*} \\
(0.151)\end{array}$ & $\begin{array}{c}0.297^{* *} \\
(0.147)\end{array}$ & $\begin{array}{c}0.291^{* *} \\
(0.148)\end{array}$ & $\begin{array}{c}0.112 \\
(0.133)\end{array}$ & $\begin{array}{c}0.128 \\
(0.133)\end{array}$ & $\begin{array}{c}0.129 \\
(0.128)\end{array}$ & $\begin{array}{c}0.132 \\
(0.128)\end{array}$ \\
\hline Reminder & $\begin{array}{c}-0.0206 \\
(0.146)\end{array}$ & $\begin{array}{c}-0.00818 \\
(0.147)\end{array}$ & $\begin{array}{l}0.0254 \\
(0.148)\end{array}$ & $\begin{array}{c}0.0109 \\
(0.150)\end{array}$ & $\begin{array}{l}-0.171 \\
(0.125)\end{array}$ & $\begin{array}{l}-0.176 \\
(0.127)\end{array}$ & $\begin{array}{c}-0.131 \\
(0.124)\end{array}$ & $\begin{array}{l}-0.143 \\
(0.125)\end{array}$ \\
\hline Focused study & $\begin{array}{c}0.0589 \\
(0.147)\end{array}$ & $\begin{array}{r}0.0847 \\
(0.149)\end{array}$ & $\begin{array}{l}0.0905 \\
(0.147)\end{array}$ & $\begin{array}{c}0.0966 \\
(0.149)\end{array}$ & $\begin{array}{l}-0.0826 \\
(0.127)\end{array}$ & $\begin{array}{r}-0.0551 \\
(0.128)\end{array}$ & $\begin{array}{r}-0.0592 \\
(0.126)\end{array}$ & $\begin{array}{l}-0.0500 \\
(0.127)\end{array}$ \\
\hline \multicolumn{9}{|l|}{ Course Completion } \\
\hline Commitment device & $\begin{array}{l}0.0872^{*} \\
(0.0510)\end{array}$ & $\begin{array}{l}0.104^{* *} \\
(0.0509)\end{array}$ & $\begin{array}{c}0.111^{* *} \\
(0.0496)\end{array}$ & $\begin{array}{l}0.107^{* *} * \\
(0.0497)\end{array}$ & $\begin{array}{c}0.0347 \\
(0.0443)\end{array}$ & $\begin{array}{c}0.0430 \\
(0.0448)\end{array}$ & $\begin{array}{c}0.0457 \\
(0.0438)\end{array}$ & $\begin{array}{c}0.0489 \\
(0.0445)\end{array}$ \\
\hline Reminder & $\begin{array}{l}-0.00234 \\
(0.0485)\end{array}$ & $\begin{array}{l}0.00423 \\
(0.0491)\end{array}$ & $\begin{array}{c}0.0150 \\
(0.0498)\end{array}$ & $\begin{array}{c}0.0108 \\
(0.0503)\end{array}$ & $\begin{array}{c}-0.0506 \\
(0.0416)\end{array}$ & $\begin{array}{l}-0.0502 \\
(0.0423)\end{array}$ & $\begin{array}{c}-0.0390 \\
(0.0428)\end{array}$ & $\begin{array}{l}-0.0332 \\
(0.0440)\end{array}$ \\
\hline Focused study & $\begin{array}{r}-0.00193 \\
(0.0488)\end{array}$ & $\begin{array}{l}0.00793 \\
(0.0494)\end{array}$ & $\begin{array}{c}0.0131 \\
(0.0492)\end{array}$ & $\begin{array}{c}0.0135 \\
(0.0498)\end{array}$ & $\begin{array}{l}-0.0461 \\
(0.0427)\end{array}$ & $\begin{array}{c}-0.0344 \\
(0.0416)\end{array}$ & $\begin{array}{l}-0.0262 \\
(0.0429)\end{array}$ & $\begin{array}{l}-0.0197 \\
(0.0426)\end{array}$ \\
\hline Demographic variables & $\mathrm{n}$ & $\mathrm{y}$ & $\mathrm{y}$ & $\mathrm{y}$ & $\mathrm{n}$ & $\mathrm{y}$ & $\mathrm{y}$ & $\mathrm{y}$ \\
\hline Course variables & $\mathrm{n}$ & $\mathrm{n}$ & $\mathrm{y}$ & $\mathrm{y}$ & $\mathrm{n}$ & $n$ & $\mathrm{y}$ & $\mathrm{y}$ \\
\hline Self-control variables & $\mathrm{n}$ & $n$ & $n$ & $\mathrm{y}$ & $n$ & $n$ & $\mathrm{n}$ & $\mathrm{y}$ \\
\hline Observations & 657 & 657 & 657 & 657 & 897 & 897 & 897 & 897 \\
\hline $\begin{array}{l}* * * \mathrm{p}<0.01, * * \mathrm{p}<0.05, * \mathrm{p}< \\
\text { install software in first week } \mathrm{p} \\
\text { the primary sample and } 3.7 \mathrm{f} \\
\text { participants. Demographic } \\
\text { income variables. Course va } \\
\text { watch some videos, reasons ta } \\
\text { improve English, type of comp } \\
\text { courses finished, previous stat } \\
\text { Self-control variables inclu }\end{array}$ & $\begin{array}{l}\text { Robust st } \\
\text { to the firs } \\
\text { all particip: } \\
\text { riables inc } \\
\text { bles incluc } \\
\text { g the course } \\
\text { er: persona } \\
\text { ics courses } \\
\text { distracting }\end{array}$ & $\begin{array}{l}\text { Idard errors } \\
\text { homework } \\
\text { ts. Baselin } \\
\text { Ide gender, } \\
\text { course got } \\
\text { general int } \\
\text { laptop, pers } \\
\text { ken, intere }\end{array}$ & $\begin{array}{l}\text { parenth } \\
\text { adline. } \mathrm{B} \\
\text { average } \mathrm{h} \\
\text { ge, age }{ }^{2}, \\
\text { finish } f \\
\text { est, relevo } \\
\text { ual deskto } \\
\text { level in }\end{array}$ & $\begin{array}{l}\text { Primary } \\
\text { ine (contro } \\
\text { sof effort } \\
\text { cation, inc } \\
\text { ertificate, } \\
\text { o school } / u \\
\text { ork compu }\end{array}$ & $\begin{array}{l}22.4 \text { for } \\
\text { me, contir } \\
\text { nish at on } \\
r k / \text { resear } \\
\text { r, previo }\end{array}$ & $\begin{array}{l}\text { primary } \\
\text {, and inc } \\
\text { pace, com } \\
\text { carrier ch } \\
\text { nline cou } \\
\text {, and ims }\end{array}$ & $\begin{array}{l}\text { who enrol } \\
\text { ents subm } \\
\text { ple and a } \\
\text { ors for } \mathrm{m} \\
\text { e some a } \\
\text { e, fun, try } \\
\text { started, } \\
\text { ance of fi }\end{array}$ & $\begin{array}{l}\text { course and } \\
\text { d is } 3.8 \text { for } \\
21.4 \text { for al } \\
n g \text { age and } \\
\text { nments, or } \\
\text { line course } \\
\text { ious onlin } \\
\text { ing course } \\
\text { ing habits }\end{array}$ \\
\hline
\end{tabular}


Table A.4: Heterogeneous Treatment Effects, Present Bias

\begin{tabular}{lcccc}
\hline \hline & $\begin{array}{c}\text { Course Effort } \\
\text { (Hours) }\end{array}$ & $\begin{array}{c}\text { Homework } \\
\text { Submitted }\end{array}$ & $\begin{array}{c}\text { Course Grade } \\
\text { (Z-score) }\end{array}$ & $\begin{array}{c}\text { Course } \\
\text { Completion }\end{array}$ \\
\hline Commitment $*$ Present-biased & -2.249 & -0.356 & -0.0673 & -0.220 \\
Reminder*Present-bias & $(6.318)$ & $(0.833)$ & $(0.103)$ & $(0.303)$ \\
& 2.994 & 0.869 & 0.0754 & 0.189 \\
Focus*Present-bias & $(5.253)$ & $(0.833)$ & $(0.0998)$ & $(0.298)$ \\
Commitment device & -0.193 & -0.290 & -0.0203 & -0.130 \\
& $(5.612)$ & $(0.824)$ & $(0.0990)$ & $(0.296)$ \\
Reminder & 6.642 & $1.106^{*}$ & $0.144^{* *}$ & $0.401^{*}$ \\
& $(4.222)$ & $(0.563)$ & $(0.0700)$ & $(0.206)$ \\
Focused study & -4.116 & -0.0890 & -0.0211 & -0.0658 \\
& $(3.605)$ & $(0.546)$ & $(0.0662)$ & $(0.195)$ \\
Present-bias & 0.674 & 0.742 & 0.0251 & 0.163 \\
& $(3.842)$ & $(0.592)$ & $(0.0713)$ & $(0.212)$ \\
Dep var mean & -1.701 & -0.195 & -0.00345 & 0.0111 \\
Demographic variables & $(4.323)$ & $(0.599)$ & $(0.0709)$ & $(0.216)$ \\
Course variables & & & & \\
Self-control variables & 22.38 & 3.730 & 0.711 & 0.289 \\
Observations & $\mathrm{y}$ & $\mathrm{y}$ & $\mathrm{y}$ & $\mathrm{y}$ \\
R-squared & $\mathrm{y}$ & $\mathrm{y}$ & $\mathrm{y}$ & $\mathrm{y}$ \\
\hline & $\mathrm{n}$ & $\mathrm{n}$ & $\mathrm{n}$ & $\mathrm{n}$ \\
& 657 & 657 & 657 & 657 \\
& 0.177 & 0.158 & 0.136 & 0.152 \\
\hline
\end{tabular}

${ }^{* * *} \mathrm{p}<0.01,{ }^{*} \mathrm{p}<0.05,{ }^{*} \mathrm{p}<0.1$ Robust standard errors in parentheses. In the pre-study survey students were asked: whether students do things in the moment that they regret later on; whether they are unable to stop themselves from doing something when they know it is wrong; whether they are good at resisting temptation; and whether they refuse things that are bad for them, even when they are fun. I combine student answers to these questions into a single index and then split the sample equally to create the Present - bias variable, which is an indicator for students who are most likely to exhibit present-biased preferences. Demographic variables include gender, age, age ${ }^{2}$, education, income, continent, and indicators for missing age and income variables. Course variables include course goals: finish for certificate, finish at own pace, complete some assignments, or watch some videos, reasons taking the course: general interest, relevant to school/work/research, career change, fun, try online course, improve English, type of computer: personal laptop, personal desktop, work computer, previous online courses started, previous online courses finished, previous statistics courses taken, interest level in course, expected course hours, and importance of finishing course. 
Figure A.1: Time-Use Summary Report
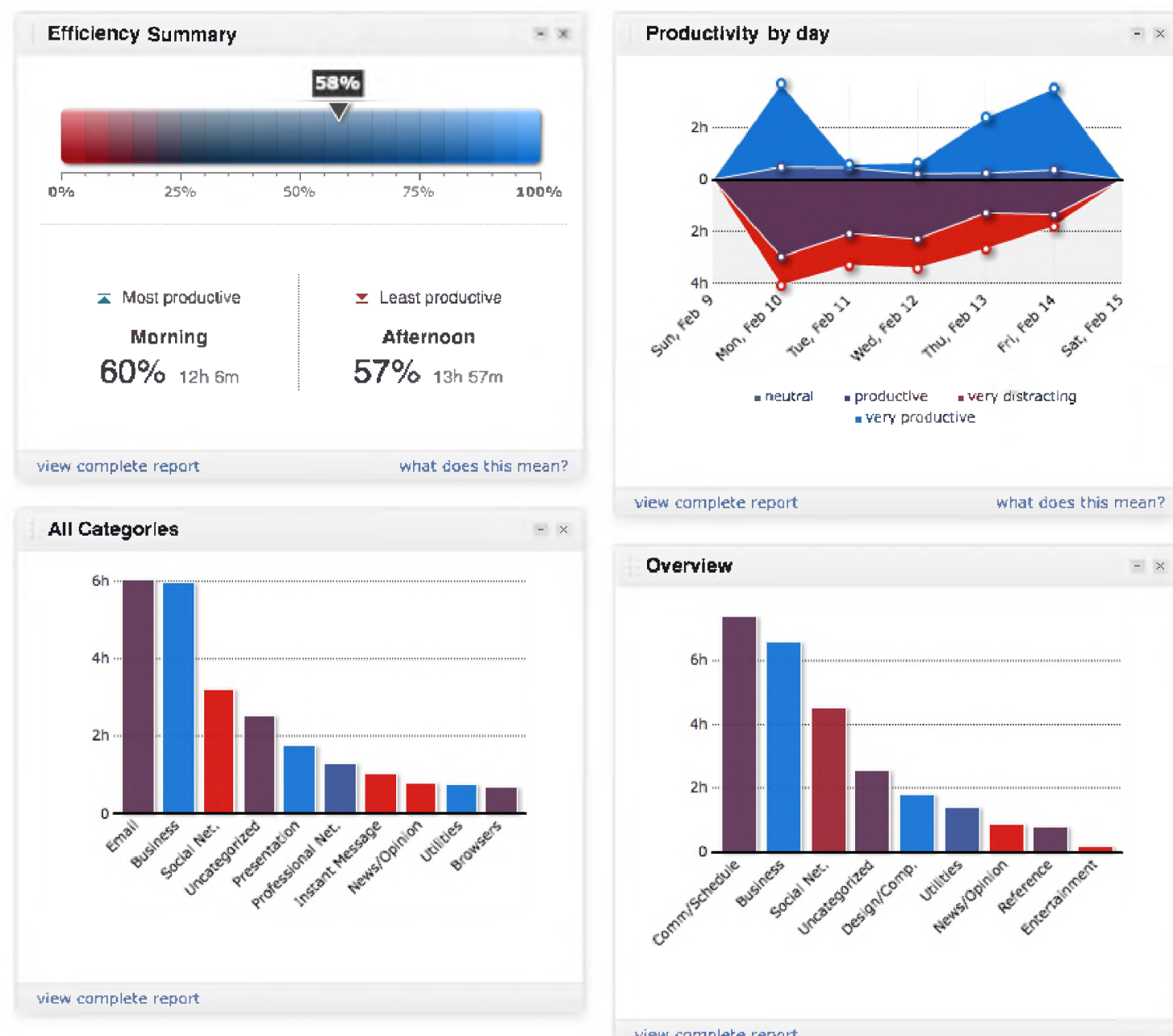

view complete repart

what does this mean?

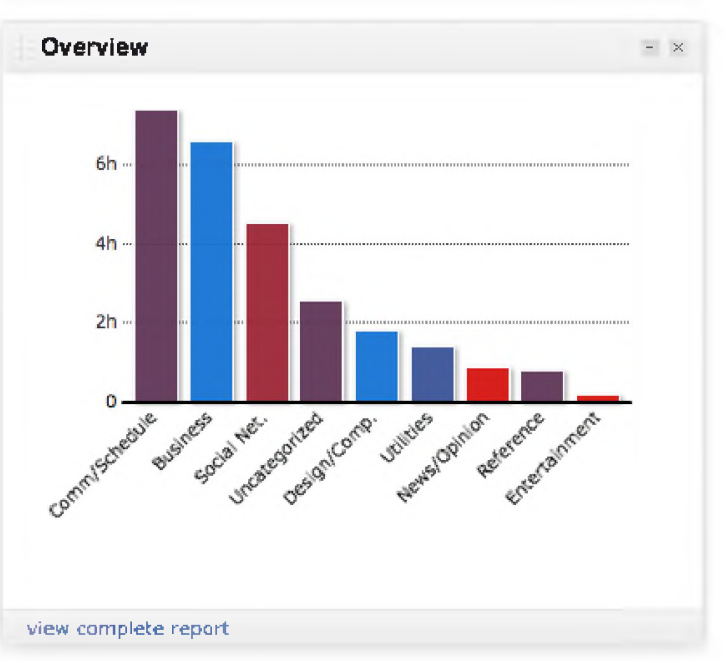


Figure A.2: Commitment Screen

Your goal: Spend less than

\subsection{Hours}

on all distracting time today.

update time

Figure A.3: Blocked Site

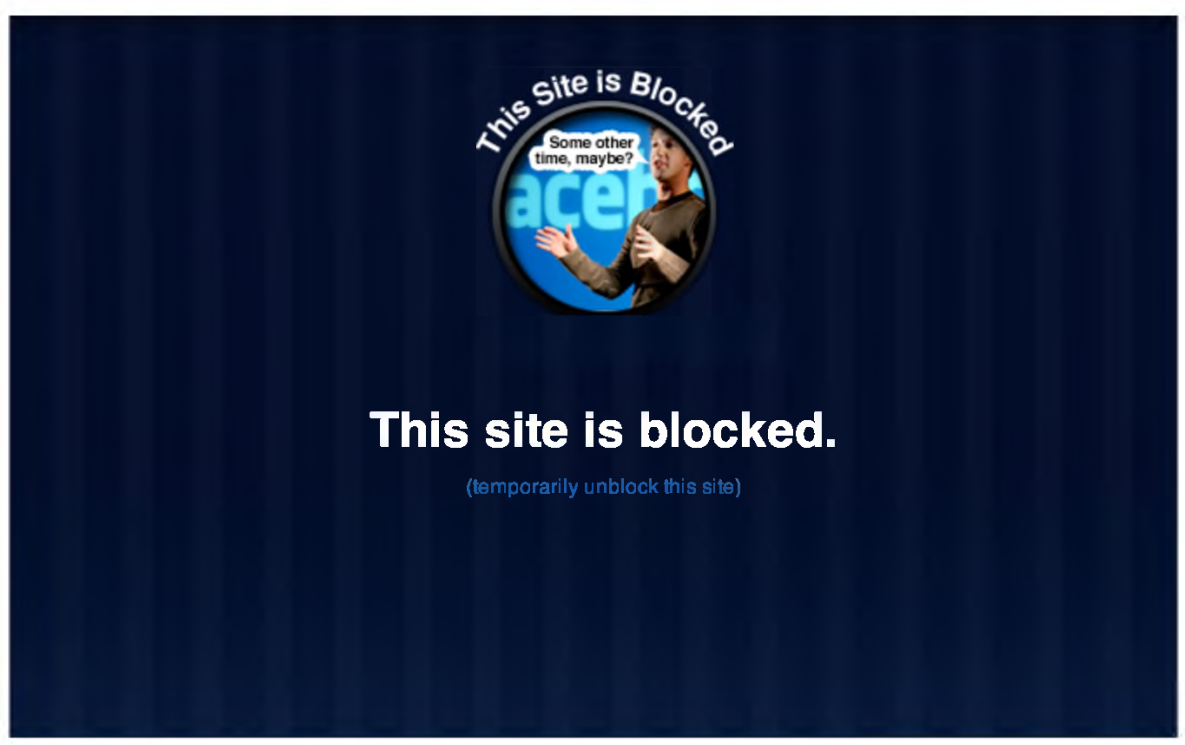


Figure A.4: Reminder

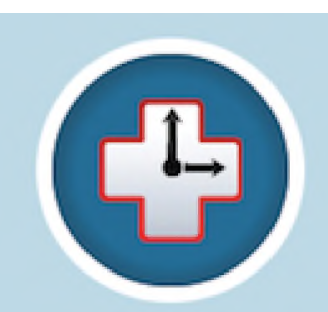

You have spent 30 minutes on distracting time today

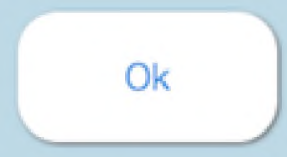

Figure A.5: Focus Study Screen

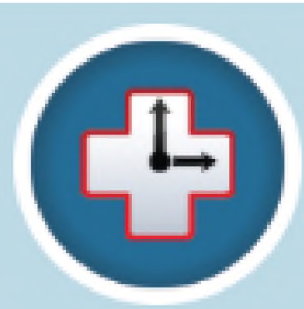

\section{Would you like to start a focused study session?}

This w block access to distracting websites for the time period you specify. 
Figure A.6: Commitment Device Patterns

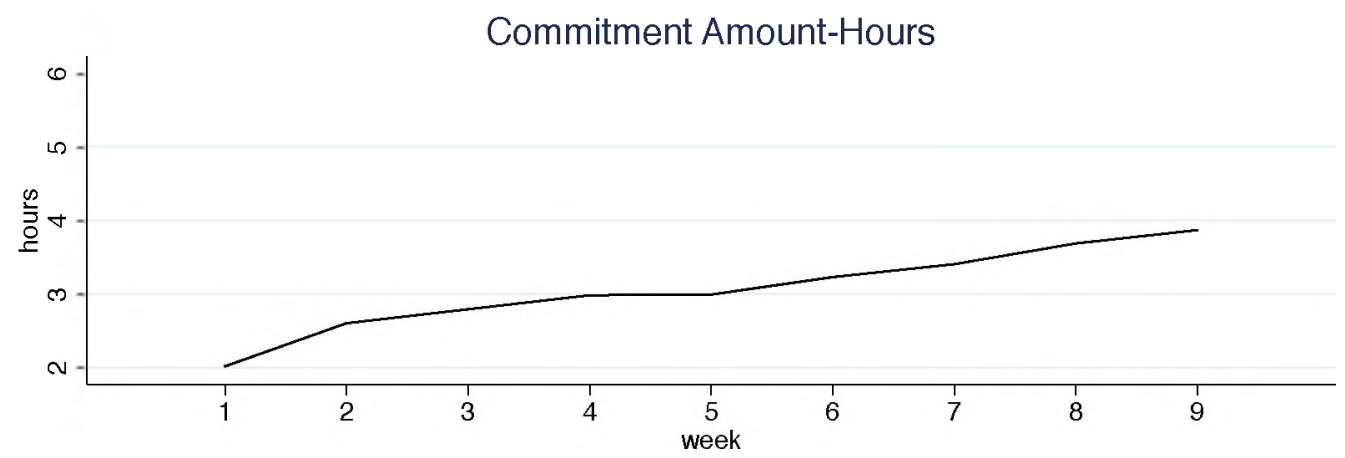

Frequency Commitments Bind

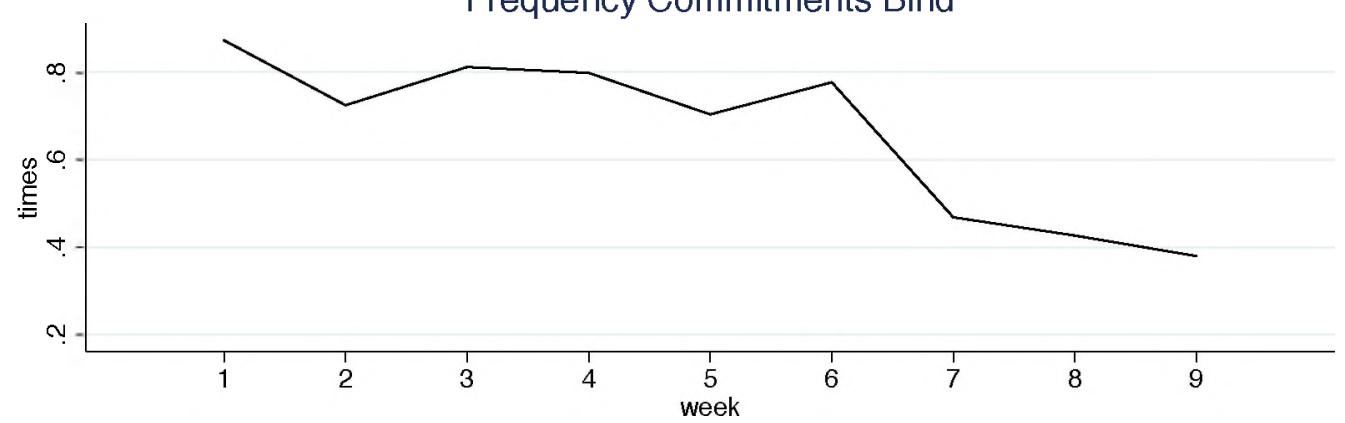


Figure A.7: Focus Study Patterns

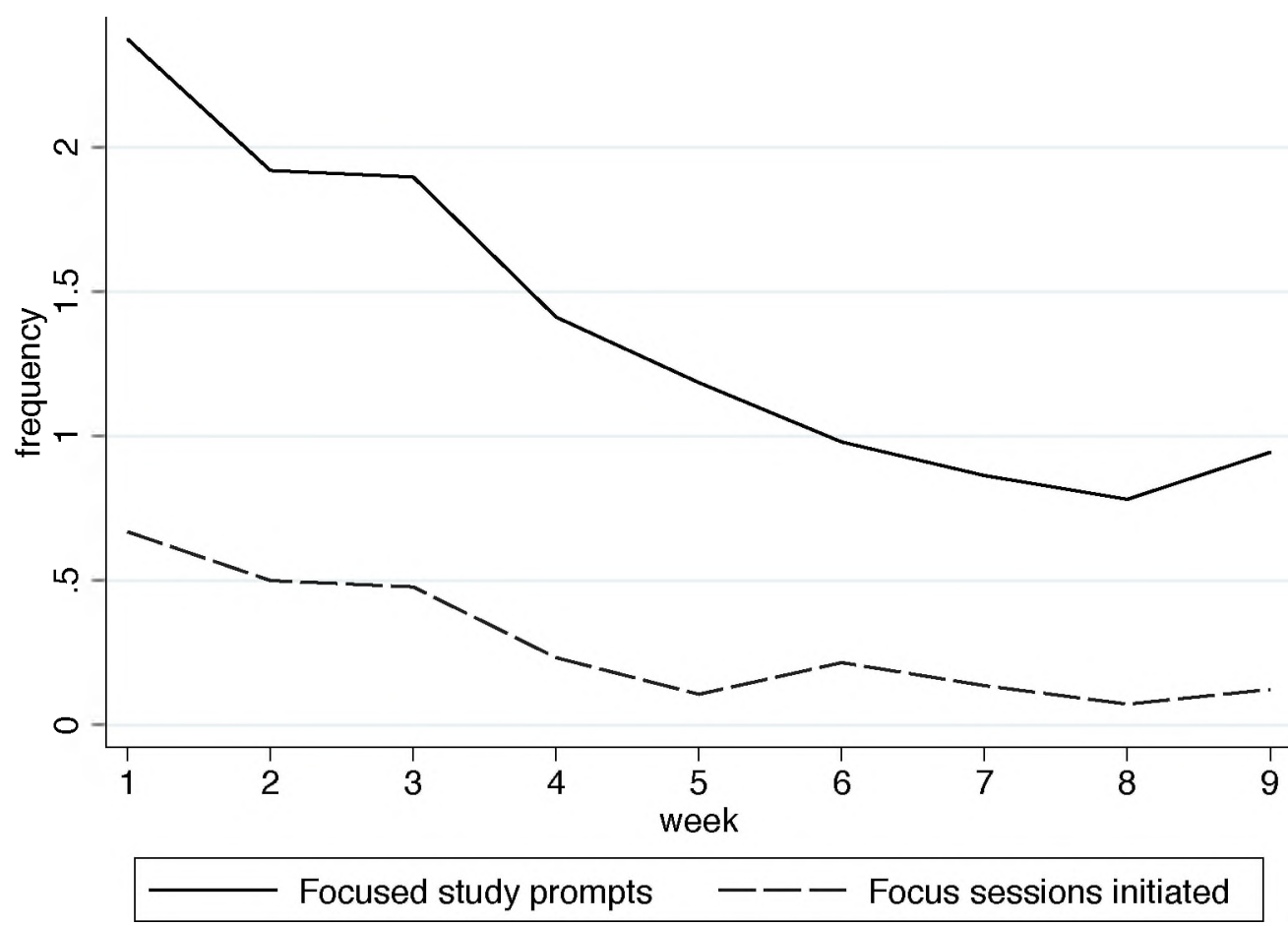




\section{B Model of Course Completion}

To generate predictions for how students respond to the commitment, reminder, and focus study treatments, I develop a simple three-period model of online course completion that allows for a student to be impatient, forget about the course, and to be distracted away from working on the course. ${ }^{40}$ The predictions of this model generalize to online course environments where students are enrolled in a course with multiple sections and must complete one course task per section. The primary predictions of this model are that the reminder treatment typically increases the probability of course completion for students who exhibit limited memory, the focus study treatment typically increases the probability of course completion for students who experience willpower depletion related to Internet distractions, and the commitment device increases course completion for students who have present-biased preferences, exhibit limited memory, or experience willpower depletion, but there are certain conditions under which the introduction of behavioral tools leads to unexpected outcomes.

In this three-period model, a student is enrolled in a two period course that requires work in one period to complete. In periods 1 and 2, the student chooses whether or not to work on the course, with the choice in each period indicated by $x_{t} \in\{0,1\}$. For reasons that will become clear, a student may choose to work on the course but not follow through to complete the coursework. Whether a student completes a task in period $t$ is indexed by $y_{t} \in\{0,1\}$. If the student completes the coursework $\left(y_{1}=1\right.$ or $\left.y_{2}=1\right)$, she receives a benefit $b$ in period 3 . Working on the course has an immediate cost $c_{t}$ that is allowed vary. ${ }^{41}$ I assume that $c_{t}$ is drawn from continuous distribution $f(c)$. I also assume that the choice not to work $\left(x_{t}=0\right)$ yields a constant flow utility $\left(u\left(x_{t}\right)\right)$ equal to 0 . In this model, students may procrastinate coursework (exhibit present-bias preferences), forget about the option of

\footnotetext{
${ }^{40}$ This model is closely related to Ericson's (2014) model of limited memory and present biased preferences and Taubinsky's (2014) model of inattention.

${ }^{41}$ While the cost $c_{t}$ represents the general opportunity cost of working on the course in period $t$, I assume recreational/distracting Internet activity is a significant contributor to this opportunity cost.
} 
Richard W. Patterson

working on the course (exhibit limited memory), or succumb to distractions after starting work on course (exhibit limited willpower).

\section{B.1 Present Biased Preferences}

When deciding whether to work on the course, students may procrastinate coursework due to present-bias preferences. I model the possibility that students exhibit present-bias preferences with a simplified quasi-hypberbolic discounting model (Laibson, 1997; O'Donoghue and Rabin, 1999). In this model, a student's discounted utility in period $t$ is represented by $U_{t}=u_{t}+\beta \sum_{\tau=t+1}^{3} u_{\tau}$, where $u_{t}$ is the flow utility in period $t$ and $\beta$ is a present-biased discount factor. ${ }^{42}$ I also assume that a student may be sophisticated or naïve about her present bias. A student is sophisticated about her present bias if she is aware that she will behave more impatiently than she would like to in the future and is naïve if she does not anticipate her future impatience. Formally, a student has beliefs about her future discount factor $\hat{\beta} \in\{\beta, 1\}$ where an student is sophisticated if $\hat{\beta}=\beta$ and naïve if $\hat{\beta}=1$.

The model, which is formally solved below, provides several predictions about the behavior of students who exhibit present-present biased preferences, but not limited memory or limited willpower. In particular, a student who exhibits present-biased preferences may fail to complete the course, even when completion is utility maximizing from a long-run perspective. The smaller the $\beta$ (or larger degree of present-bias), the more likely an student is to procrastinate coursework that maximizes long-run utility. Additionally, naïvete about present bias makes a student less likely to complete the course in the first period. This is because a naive student anticipates that she will behave patiently in the future and is more willing to delay coursework than is utility maximizing.

\footnotetext{
${ }^{42}$ Quasi-hyperbolic discounted utility models often include an exponential discount factor $\delta$ such that $U_{t}=u_{t}+\beta \sum_{\tau=t+1}^{3} \delta^{t} u_{\tau}$. I make the simplifying assumption that $\delta=1$. Additionally, I assume that if no other behavioral factors are present, a student follows through on any decision to work on course such that $y_{t}=x_{t}$.
} 
Richard W. Patterson

While students who exhibit present-bias preferences are likely to behave more impatiently than they would like to from a long-run perspective, commitment devices can increase the probability that present-bias students finish the course. In this setting, I introduce a commitment device technology that increases the future cost of spending time on distracting Internet activities. The change in the relative cost of coursework induced by the commitment device in period $t$ is represented by $\kappa_{t}$. If a student in period 1 is given the option to set a commitment for period 2, she will to choose a commitment level that increases the probability she completes the course $\left(\kappa_{2}<0\right)$ if she is (1) present biased, (2) sophisticated about her present bias, (3) the expected benefit of choosing $\kappa_{2}$ exceeds the cost. ${ }^{43}$ When students are present biased and other behavioral factors are absent, commitment devices unambiguously increase a sophisticated student's expected utility.

\section{B.2 Limited Memory}

In addition to being present biased, students may forget about coursework. To incorporate the possibility that students may forget about the choice to work on the course, I allow for the probability of considering the course $\left(\rho_{t}\right)$ to be less than 1 , such that $\rho_{t} \in(0,1]$. I also let $\alpha_{t} \in\{0,1\}$ be an indicator for whether an individual is attentive in period $t$. I assume that forgetting is a transitory "slipping of the mind" (Ericson, 2014) that is independent of whether or not a task was remembered previously. ${ }^{44}$ Just as a student may not anticipate their future present-biased tendencies, a student may or may not be aware of her tendency to forget about coursework $\hat{\rho}_{t} \in\left\{\rho_{t}, 1\right\}$, and is sophisticated about limited memory if $\hat{\rho}_{t}=\rho_{t}$

\footnotetext{
${ }^{43}$ Specifically, a student will choose a commitment if there exists a $\kappa *$ such that $\left(P\left[x_{2} \mid \kappa_{2}=\kappa *\right]-P\left[x_{2} \mid \kappa_{2}=\right.\right.$ $0) b-\left(1-P\left[x_{2} \mid \kappa_{2}=\kappa *\right]\right) \kappa_{2}>0$. When other behavior factors are absent, a commitment device set in period 1 for period 2 increases the overall probability that a student completes the course, but decreases the probability the probability that a student completes the course in period 1 .

${ }^{44}$ Some previous work has assumed that limited memory follows a dynamic process where the probability of forgetting to be increasing in previous memory failure (Mullainathan, 2002; Ericson, 2014; Taubinsky, 2014). In the most extreme case Ericson (2014), assumes that once something is forgotten it can never be remembered again.
} 
and naïve if $\hat{\rho}_{t}=1$.

When other behavioral factors are absent, an increase in the probability that students remember the course $\left(\rho_{t}\right)$ unambiguously increases the probability that students remember the course. Although an increase in $\rho_{t}$ in either period 1 or 2 increase the overall probability that a student completes the course, awareness of a coming reminder in period 2 decreases the probability that a sophisticated student $\left(\hat{\rho}_{t+1}=\rho_{t+1}\right)$ completes the course in period 1.

\section{B.3 Limited Willpower}

Finally, I assume that after a student chooses to work on the course, she may become distracted and fail to complete the coursework she chose to do. I let $\pi_{t} \in(0,1]$ represent the probability that a student has sufficient willpower to complete the coursework she chooses and $\sigma \in\{0,1\}$ be an indicator for whether or not the student finishes the coursework that she starts such that $y_{t}=\sigma x_{t}$. I assume that where $\pi_{t}$ is decreasing in the level of distractions to which she is exposed. I also assume that students who are distracted from completing the task do not incur the cost of work $c_{t} \cdot{ }^{45}$ Just as with present-biased preferences, I allow for naïvete and sophistication about limited willpower $\hat{\pi}_{t} \in\left\{\pi_{t}, 1\right\}$. An increase $\pi_{t}$ in period 1 or 2 increases the overall probability that a student completes the course, but awareness of a coming increase in the probability of following through in period 2 reduces the probability that a sophisticated student completes the course in period 1.

\section{B.4 Combining Behavioral Factors}

When present-bias, limited memory, and limited willpower are isolated, the impact of commitment devices, and factors that increase the probability of remembering the course (reminders) and following through on a decision to work on the course (focusing tools) have

\footnotetext{
${ }^{45}$ This assumption implies that students are distracted from completing the task shortly after deciding to work on the task. While this pattern matches observed behavior, the model generates similar predictions when this assumption is relaxed.
} 
Richard W. Patterson straightforward impacts on utility and the probability that students complete the course. However, when behaviors are combined, behavioral tools may have unanticipated impacts on student outcomes. First, a student who is sophisticated about her time-inconsistent preferences, but naïve about her limited memory and limited willpower may choose to utilize a commitment device that reduces her overall utility. Naïvete leads a student to overestimate the probability that she will complete the course with the help of a commitment device, and may lead a student to choose a commitment device that reduces her overall well-being.

Furthermore, a student who is sophisticated about her limited memory but naïve about her limited willpower or present bias may actually be less likely to complete a course when she knows that she will get a reminder in the following period. Naïvete about limited willpower or present bias leads a student to overestimate the impact of a reminder in the following period. An increase in the anticipated probability of remembering coursework in the future decreases the probability that a student chooses to work on the course in the current period. If a student sufficiently overestimates the impact of a reminder in the future then the reminder may decrease the overall probability that she completes the course. Symmetrically, awareness of the availability a future focusing tool may make a student who is is sophisticated about her limited willpower but naïve about her present bias or limited memory less likely to complete the course.

\section{B.5 Model Solution}

Below is a full solution to the model which incorporates present bias and beliefs over present bias $(\beta, \hat{\beta})$, limited memory $\left(\rho_{t}, \hat{\rho}_{t}\right)$, and limited willpower $\left(\pi_{t}, \hat{\pi}_{t}\right)$. Students solve for their utility maximizing choice by backwards induction.

In the period 2, the final decision period, a student will choose to work on the course if she considers the choice to work on the course, and the discounted benefit exceeds the cost. 
Richard W. Patterson

Formally, the choice to work on the course can be characterized by the following:

$$
x_{2}= \begin{cases}1, & \text { if } \alpha_{2}=1, y_{1}=0, \text { and } \hat{\pi}_{2} c_{2}+\hat{\pi}_{2} \beta b>0 \\ 0, & \text { otherwise }\end{cases}
$$

where $\alpha_{2}$ is an indicator of whether the student considers the choice of coursework, $\hat{\pi}_{2}$ is the belief of the probability that the student will complete a task she begins, $\beta$ is the present-bias discount factor, $c_{2}$ the cost of completing the course, and $b$ the benefit of completing the course. Note that a student will never work on the course if $y_{1}=1$, because there is no benefit to working on the course if the course was already completed in period 1 .

The probability that a student completes the course in the second period $\left(\operatorname{Pr}\left[y_{2}=1\right]\right)$ given that $y_{1}=0$, depends on the distribution of costs $f(c)$, the discounted benefit of action $\beta b$, and the probability of considering the course $\rho_{2}$ and the probability of following through with a decision to work on the course $\pi_{2}$, such that:

$$
\begin{aligned}
\operatorname{Pr}\left[y_{2}=1 \mid y_{1}=0\right] & =\pi_{2} \rho_{2} \int_{-\beta b}^{\infty} f(c) d c \\
& =\pi_{2} \rho_{2}(1-F(-\beta b))
\end{aligned}
$$

where $F(\cdot)$ is the cumulative distribution function (CDF) of $f(c)$ and other variables are as previously specified.

In period 1, a student will choose to work on the course if the net value of working on the course in period $1\left(c_{1}+\beta b\right)$ exceeds $\hat{v}_{(2,0)}$ - the expected value of the choice to work on course in period 2. Formally:

$$
x_{1}= \begin{cases}1, & \text { if } \alpha_{1}=1, \text { and } \hat{\pi}_{1} c+\beta \hat{\pi}_{1} b+\left(1-\hat{\pi}_{1}\right) \hat{v}_{2,0}>\hat{v}_{2,0} \\ 0, & \text { otherwise }\end{cases}
$$


where:

$$
\hat{v}_{2,0}=\beta \hat{\rho}_{2} \hat{\pi}_{2} \int_{-\hat{\beta} b}^{\infty}(c+b) f(c) d c
$$

and other variables are as previously specified. Note that students may anticipate the possibility of choosing to work on the course but not follow through, and that part of the value of choosing $x_{1}=1$ in period 1 is $\left(1-\hat{\pi}_{1}\right) \hat{v}_{2,0}$, or the expected probability of failing to complete coursework multiplied by the expected value of value of the choice of $x$ in period 2. Given the choice above, the probability that a student completes the course in the first period is:

$$
\begin{aligned}
\operatorname{Pr}\left[y_{1}=1\right] & =\rho_{1} \pi_{1} \int_{-\beta b+\hat{v}_{2,0}}^{\infty} f(c) d c \\
& =\pi_{1} \rho_{1}\left(1-F\left(-\beta b+\hat{v}_{2,0}\right)\right)
\end{aligned}
$$

Having calculated the conditional probability of completing the course in the second period, $\operatorname{Pr}\left[y_{2}=1 \mid y_{1}=0\right]$ and the unconditional probability of completing the course in the first period, the total probability of completing the course can be expressed by the following equation:

$$
\begin{aligned}
& \operatorname{Pr}[\mathbf{y}=1]=\rho_{1} \pi_{1} \int_{-\beta b+\hat{v}_{2,0}}^{\infty} f(c) d c+\left[1-\rho_{1} \pi_{1} \int_{-\beta b+\hat{v}_{2,0}}^{\infty} f(c) d c\right] \rho_{2} \pi_{2} \int_{-\beta b}^{\infty} f(c) d c \\
& =\pi_{1} \rho_{1}\left(1-F\left(-\beta b+\hat{v}_{2,0}\right)\right)+\left[1-\pi_{1} \rho_{1}\left(1-F\left(-\beta b+\hat{v}_{2,0}\right)\right)\right] \pi_{2} \rho_{2}(1-F(-\beta b))
\end{aligned}
$$

\section{B.6 Comparative Statics}

In this section I examine how changes in the probability that students remember the choice to work on the course $\left(\rho_{t}\right)$, the probability that students have sufficient willpower to complete coursework $\left(\pi_{t}\right)$, and the relative cost of coursework $\left(\kappa_{t}\right)$ impact course completion. 


\section{B.6.1 Changes in the probability in remembering}

Increasing the probability that students consider the course tends to increase the probability that students complete coursework. However, the magnitude and direction of the impact of changing $\rho_{t}$ depends on the period $t$ and value of other parameters in the model.

The impact of increasing $\rho_{1}$ on the probability that a student completes the course is:

$$
\frac{\partial \operatorname{Pr}[y=1]}{\partial \rho_{1}}=\left[1-\rho_{2} \pi_{2} \int_{-\beta b}^{\infty} f(c) d c\right] \pi_{1} \int_{-\beta b+\hat{v}_{2,0}}^{\infty} f(c) d c
$$

and the impact of increasing $\rho_{2}$ on the probability of course completion is:

$$
\begin{gathered}
\frac{\partial \operatorname{Pr}[y=1]}{\partial \rho_{2}}=-\rho_{1} \pi_{1}\left[1-\rho_{2} \pi_{2} \int_{-\beta b}^{c_{l}} f(c) d c\right] f\left(-\beta b+\hat{v}_{2,0}\right) \frac{\partial \hat{v}_{2,0}}{\partial \rho_{2}} \\
+\left[1-\rho_{1} \pi_{1} \int_{-\beta b+\hat{v}_{2,0}}^{\infty} f(c) d c\right] \pi_{2} \int_{-\beta b}^{\infty} f(c) d c
\end{gathered}
$$

where

$$
\frac{\partial \hat{v}_{2,0}}{\partial \rho_{2}}= \begin{cases}\beta \hat{\pi}_{2} \int_{-\hat{\beta} b}^{c_{l}}(c+b) f(c) d c, & \text { if } \hat{\rho}_{2}=\rho_{2} \\ 0, & \text { if } \hat{\rho}_{2}=1\end{cases}
$$

The equations above highlight several properties of increasing the probability of remembering the course. Equation 5 shows that increasing the probability of $\rho_{1}$ unambiguously increases the probability that a student completes her coursework. Furthermore the impact of an increase in $\rho_{1}$ on completion is increasing in $\pi_{1}$ and decreasing in $\rho_{2}, \pi_{2}, \hat{\rho}_{2}, \hat{\pi}_{2}$, and $\hat{\beta}$. Intuitively, an increase in the probability that a student remembers the choice to work on the course on the first period has the largest impact for students who are likely to follow through on their choice to work and who are unlikely (and aware that they are unlikely) to complete the coursework in the second period.

Equation 6 shows the impact of increasing the probability that a student will remember 
Richard W. Patterson

the choice to work $\left(\rho_{2}\right)$ in period 2 . If a student is naïve about her tendency to forget, then the first line of Equation 6 is equal to zero, and the increase in the probability in unambiguously positive. However, if a student is aware that she of the increase in $\rho_{2}$ in period 1 , the first line of Equation 6 shows the impact of the increase in $\rho_{2}$ is diminished, and may even be negative. Sophistication about $\rho_{2}$ further diminishes the probability of course completion if individuals are naïve about limited willpower and present-bias preferences.

\section{B.6.2 Changes in the probability that students follow through on coursework}

Increasing the probability that students follow through on a decision they make to work $\left(\pi_{t}\right)$ has symmetric implications to increasing the probability that students remember to consider the course. The impact of increasing the probability that a student will follow through with a choice in period $1\left(\pi_{1}\right)$ on the probability that students complete the course is:

$$
\frac{\partial \operatorname{Pr}[y=1]}{\partial \pi_{1}}=\left[1-\rho_{2} \pi_{2} \int_{-\beta b}^{\infty} f(c) d c\right] \rho_{1} \int_{-\beta b+\hat{v}_{2,0}}^{\infty} f(c) d c
$$

And the impact of increasing the probability that a student follows through with a choice in period $2\left(\pi_{2}\right)$ on course completion is:

$$
\begin{gathered}
\frac{\partial \operatorname{Pr}[y=1]}{\partial \pi_{2}}=-\rho_{1} \pi_{1}\left[1-\rho_{2} \pi_{2} \int_{-\beta b}^{c_{l}} f(c) d c\right] f\left(-\beta b+\hat{v}_{2,0}\right) \frac{\partial \hat{v}_{2,0}}{\partial \pi_{2}} \\
+\left[1-\rho_{1} \pi_{1} \int_{-\beta b+\hat{v}_{2,0}}^{\infty} f(c) d c\right] \rho_{2} \int_{-\beta b}^{\infty} f(c) d c
\end{gathered}
$$

Equation 7 shows that tie impact of increasing $\pi_{1}$ increases the probability that a student completes the course, and that the impact of increasing $\pi_{1}$ is increasing in $\rho_{1}$ and decreasing

in $\rho_{2}, \pi_{2}, \hat{\rho}_{2}, \hat{\pi}_{2}$, and $\hat{\beta}$. Equation 8 shows that increasing $\pi_{2}$ has an unambiguously positive impact on completion for who do not believe they may fail to follow through on their decision to complete the course, but the impact is reduced and may even be negative for students 
Richard W. Patterson who are sophisticated about their limited willpower and naïve about their limited memory or present bias.

\section{B.6.3 Changes in the relative costs in coursework}

A student may have access to a technology that changes the cost of the alternate choice to coursework in period $t$. An change of in the cost of the alternate choice leads to a corresponding shift in the the relative cost of coursework, such that the new cost of the coursework is $c_{t}+\kappa_{t}$. If $c_{t}+\kappa_{t}$ is substituted for $c_{t}$ in the student's utility maximization problem, the resulting probability of completing the course is:

$$
\operatorname{Pr}[\mathbf{y}=1]=\rho_{1} \pi_{1} \int_{-\beta b+\kappa_{1}+\hat{v}_{2,0}}^{\infty} f(c) d c+\left[1-\rho_{1} \pi_{1} \int_{-\beta b+\kappa_{1}+\hat{v}_{2,0}}^{\infty} f(c) d c\right] \rho_{2} \pi_{2} \int_{-\beta b+\kappa_{2}}^{\infty} f(c) d c
$$

where:

$$
\hat{v}_{2,0}=\beta \hat{\rho}_{2} \hat{\pi}_{2} \int_{-\hat{\beta} b+\kappa_{2}}^{\infty}(c+b) f(c) d c
$$

Increasing the relative cost of coursework in period $1\left(\kappa_{1}\right)$ has the following impact on course completion:

$$
\frac{\partial \operatorname{Pr}[y=1]}{\partial \kappa_{1}}=-\rho_{1} \pi_{1}\left[1-\rho_{2} \pi_{2} \int_{-\beta b+\kappa_{2}}^{\infty} f(c) d c\right] f\left(-\beta b+\kappa_{1}+\hat{v}_{2,0}\right)
$$

while increasing the relative cost of coursework in period $2\left(\kappa_{2}\right)$ had the following impact on course completion:

$$
\begin{gathered}
\frac{\partial \operatorname{Pr}[y=1]}{\partial \kappa_{2}}=-\rho_{1} \pi_{1}\left[1-\rho_{2} \pi_{2} \int_{-\beta b+\kappa_{2}}^{\infty} f(c) d c\right] f\left(-\beta b+\kappa_{1}+\hat{v}_{2,0}\right) \frac{\partial \hat{v}_{2,0}}{\partial \kappa_{2}} \\
-\rho_{2} \pi_{2}\left[1-\rho_{1} \pi_{1} \int_{-\beta b+\kappa_{1}+\hat{v}_{2,0}}^{\infty} f(c) d c\right] f\left(-\beta b+\kappa_{2}\right)
\end{gathered}
$$


Richard W. Patterson

where:

$$
\frac{\partial \hat{v}_{2,0}}{\partial \kappa_{2}}=-\beta \hat{\rho}_{2} \hat{\pi}_{2}\left((1-\hat{\beta}) b+\kappa_{2}\right) f\left(-\hat{\beta} b+\kappa_{2}\right)
$$

Equation 10 shows the unsurprising result that an increase in $\kappa_{1}$, the relative cost of course completion, leads to a decrease in the probability of course completion. The first line of Equation 11 shows an anticipated increase the cost of course completion in period 2 increases the likelihood a student completes the course in period 1 line 2 of Equation 11 indicates that higher period 2 costs decrease the probability that a student completes the course in period 2. A comparison of terms in the first and second line of Equation 11 indicates that the overall impact of increasing the relative cost of the course decreases the total probability that students complete the course.

\section{B.7 Impact of Treatments on Model Parameters}

Each of the commitment device, reminder, and focusing treatments are designed to target different aspects of time-management problems. Below I describe how the treatments in this study are likely to impact different model parameters.

\section{B.7.1 Commitment Device}

The commitment device treatment prompts students via a daily email set to limits for the amount of distracting time they spend on their computer. This treatment is likely to impact several parameters in the model. First, if students experience limited memory, then daily emails and blocked websites are likely to increase $\rho_{t}$-the probability that students consider the course. Second, if students have limited willpower, the commitment device may also reduce $\pi_{t}$ - the probability that a student follows through on a decision to work on the course. When a commitment device binds, then distractions are removed, which may increase the probability that students follow through on a decision to work on the course $\left(\pi_{t}\right)$. Finally 
Richard W. Patterson a pre-commitment to a restrictive time-limit decreases the relative cost of working on the course in a future period by $\kappa_{t+1}$, which increases the probability of completing the course in the following period. Given the predictions of the model, the commitment device may increase course completion by addressing limited memory (through increasing $\rho_{t}$ ), limited willpower (through increasing $\pi_{t}$ ), or present bias preferences (through decreasing $\kappa_{t+1}$ ).

\section{B.7.2 Reminder}

The reminder treatment provides students with a reminder after each half hour of distracting time which includes a link to the course website. If students exhibit limited memory, this reminder is likely to increase the probability that students remember the decision to work on the course $\rho_{t}$. It is also possible that the reminder increases the cost of distracted Internet browsing, either by annoyance or guilt. If the reminder decreases the relative cost of coursework $\left(\kappa_{t}\right)$ by making distracted Internet time less enjoyable, this may lead to increase the probability of course completion. This, however, is not evidence of present-bias, limited memory, or limited willpower-a decrease in the relative cost of coursework is likely to increase completion for all students, including those who experience no behavioral issues. Therefore, a positive impact of the reminder treatment is consistent with a model limited memory, but does not rule out other models of behavior.

\section{B.7.3 Focus Tool}

The focus tool allows students to block out distracting websites for up to 60 minutes upon going to the course website. If a student has limited willpower and the presence of Internet distractions reduce the probability that she completes coursework she decides to do, then blocking distractions may increase the probability that she follows through with her decision to work on the course $\left(\pi_{t}\right)$. Because a student must go to the course in order to interact with the focus tool, the focus tool is unlikely to impact on the probability that students consider 
Richard W. Patterson the course $\rho_{t}$. Also, it is difficult for students to use the focus tool as a commitment device because choosing to utilize the focus tool impacts the relative costs of coursework for no more than an hour, and the focus tool takes immediate effect. As a result, a response to the focus tool is unlikely to be explained by present-bias ${ }^{46}$ or limited memory, but is consistent with a model of limited willpower.

\footnotetext{
${ }^{46}$ To make this assertion, I assume that students treat time within an hour as being within the present period.
} 